\title{
Measuring Business Cycles with Structural Breaks and Outliers: Applications to International Data*
}

\author{
Tatsuma Wada ${ }^{\dagger}$ \\ Wayne State University
}

\author{
Pierre Perron ${ }^{\ddagger}$ \\ Boston University
}

This Version: February 8, 2014

\begin{abstract}
This paper first generalizes the trend-cycle decomposition framework of Perron and Wada (2009) based on unobserved components models with innovations having a mixture of normals distribution, which is able to handle sudden level and slope changes to the trend function as well as outliers. We investigate how important are the differences in the implied trend and cycle compared to the popular decomposition based on the Hodrick and Prescott (HP) (1997) filter. Our results show important qualitative and quantitative differences in the implied cycles for both real GDP and consumption series for the G7 countries. Most of the differences can be ascribed to the fact that the HP filter does not handle well slope changes, level shifts and outliers, while our method does so. Then, we reassess how such different cycles affect some socalled "stylized facts" about the relative variability of consumption and output across countries.
\end{abstract}

JEL Classification: C22, E32.

Key Words: Trend-Cycle Decomposition, Unobserved Components Model, International Business Cycle, Non Gaussian Filter.

\footnotetext{
*This paper has been circulated under the title "An Alternative Trend-Cycle Decomposition using a State Space Model with Mixtures of Normals: Specifications and Applications to International Data." We are grateful to James Morley, Charles Nelson, Tara Sinclair and seminar participants at Purdue and Simon Fraser Universities, the Federal Reserve Banks of Dallas and Richmond, the Society for Nonlinear Dynamics and Econometrics Annual Meeting at Washington University for their useful comments.

${ }^{\dagger}$ Department of Economics, Wayne State University, 656 W. Kirby St., Detroit MI 48202 (tatsuma.wada@wayne.edu)

${ }_{\ddagger}^{\ddagger}$ Department of Economics, Boston University, 270 Bay State Road, Boston MA 02215 (perron@bu.edu)
} 


\section{Introduction}

Studies of business cycles have been one of the most important and attractive fields in macroeconomics. Since, at least Burns and Mitchell (1946), a variety of methods have been utilized to measure business cycle, thereby inspiring theoretical models that explain the features of the business cycles; alternatively, models are often evaluated on how well they mimic the characteristics of the business cycles that are observed in the data. The seminal work of Burns and Mitchell (1946) initiated the modern study of business cycle measurement. However, subsequently researchers adopted a different approach focusing more on easily applicable mechanical methods that obviate subjective evaluations. A major reason why economists have focused on this measurement issue is that most macroeconomic models pertain to business cycles or cyclical component. Faced with trending data, there is accordingly a need to separate the trend and the cycle.

Among others, popular decomposition methods are: the Beveridge-Nelson (1981) decomposition based on unconstrained ARIMA models (Campbell and Mankiw, 1987, Watson, 1986, Cochrane, 1988, for example); the Unobserved Components models (Clark, 1987, Morley et al., 2003; hereafter UC models); the Hodrick and Prescott (1997) (hereafter HP) filter; and the Band-Pass filter (Baxter and King, 1999).

Recently, Perron and Wada (2009) showed the importance of accounting for structural changes in the trend function of a time series when performing a trend-cycle decomposition. They considered the US real GDP series and argued that once a change in the slope of the trend function is allowed in 1973:1, standard unobserved components models and the Beveridge-Nelson decomposition deliver the same trend and cycle, the trend being a simple piecewise deterministic linear function. They also proposed a generalized unobserved components model where the errors affecting the slope of the trend function are drawn from a mixture of normals distribution. ${ }^{1}$ This permits sudden changes in the slope occurring occasionally at dates that need not be pre-specified but which are the outcome of the smoothed trend estimate. Notably, Luo and Startz (2013) recently confirmed Perron and Wada's (2009) finding using a Bayesian methodology.

While a number of previous studies have considered allowing for a change in the slope of the trend within the context of UC models, e.g., Mitra and Sinclair (2012) for the G7 countries, in our view allowing for the possibility of changes in only the slope of the trend

\footnotetext{
${ }^{1}$ They also consider such a distribution for the shock to the cyclical component to allow different variances in expansions and recessions.
} 
function is insufficient. As discussed in Section 2, when dealing with real GDP series for the G7 countries, one is also faced with the problems of level shifts and severe outliers. Our aim is, therefore, first to generalize the trend-cycle decomposition framework of Perron and Wada (2009) and extend their algorithm to estimate the resulting structural models. Secondly, we wish to investigate how important are the differences in the implied trend and cycle for the various countries compared to other methods. Since, in empirical macroeconomic analyses, the most frequently used detrending procedure is the HP filter, we shall restrict our comparative analysis to our detrending procedure and the HP filter. Our results will show important qualitative and quantitative differences in the implied cycles for both real GDP and consumption series for the G7 countries. As also pointed out by Dueker and Nelson (2006), who compared their method which uses a latent business-cycle index that is negative during recessions and positive during expansions based on the NBER classification, most of the differences can be ascribed to the fact that the HP filter does not handle well slope changes, level shifts and outliers, while our method does so. Hence, our results first lead to a different picture of the cyclical component of important macroeconomic time series. Third, we assess how such different cycles affect some so called "stylized facts" about the relative variability of consumption and output across countries. Our results show again some important differences. In particular, we find that i) the volatility of consumption is not necessarily smaller than that of output, ii) compared to the results using the HP filter, there are more cases for which cross-country correlation in consumption is higher than that in output; and iii) unlike the majority of previous studies, including Canova et al. (2007) and Stock and Watson (2005), there is not much evidence for the hypothesis that the characteristics of countries' business cycles can be categorized into three groups of countries, namely, European (France, Germany, and Italy), Japan, and English speaking countries (Canada, UK and US). ${ }^{2}$

The plan of the paper is the following. Section 2 motivates the subsequent analyses by looking at the salient features of real GDP series for the G7 countries. We establish the theoretical framework for the trend-cycle decompositions and the selection of models for each country in Section 3. Section 4 presents the results for the trend-cycle decomposition of the real GDP and consumption series or the G7 countries and compare the results to those obtained with an HP filter. Section 5 reassesses the findings about important measures of cyclical movements in output and consumption across the G7 countries using our trend-

\footnotetext{
${ }^{2}$ Doyle and Faust (2005) considered structural breaks in the growth rates of G7 output, consumption, and investment. They also document a reduced cross-country correlation within the groups.
} 
cycle decomposition, with emphasis on the relative volatilities of the cyclical components of output (real GDP) and consumption, and the cross-country correlations in these components. Section 6 offers brief concluding comments. An appendix contains technical details.

\section{Motivation}

Figures 1 and 2 present the seasonally adjusted (log) real GDP and real consumption series for the G7 countries using postwar quarterly series from 1960.I through 2011.IV. The data ${ }^{3}$ are from the Organization for Economic Co-operation and Development's (OECD) Quarterly National Accounts. These graphs reveal a number of interesting features. First, most countries show a decline in the rate of growth occurring near 1973. This is a feature that has received a lot of attention. For example, Perron (1989) argues that once one allows for a change in the slope of the trend function in 1973:1, one can reject the hypothesis that the US real GDP series contains a unit root (see Perron, 1997, for evidence pertaining to real GDP series for the G7 countries). Also, Bai, Lumsdaine and Stock (1998) estimate a multivariate model of the growth rates of real GDP for the G7 countries imposing a common break. They find statistical evidence for a change in mean with a $90 \%$ confidence interval that covers the period 1972:2-1975:2. More evidence is presented in Perron and Yabu (2009) who find a statistically significant change in the slope of the trend function for all countries allowing the noise component to be stationary or to have an autoregressive unit root. In all such studies the change is modelled as being sudden (i.e., a structural change at some date). ${ }^{4}$ This is important since standard detrending methods such as the HP filter are able to allow for a decrease in the rate of growth through time but not in a sudden fashion.

Another feature that is present in many series are more or less sudden level shifts. Such level shifts occur for Germany in the late 1970s and early 1990s; and for the UK in the early 1980s. It is especially evident for the case of the German data retrieved in 2004 prior to a revision to account for the re-unification (labeled "Germany-unrevised"), which shows a dramatic increase in 1991 at the time of the re-unification. ${ }^{5}$ Another type of aberrant pattern is present in the case of France for which an extreme outlier occurs in 1968 in the

\footnotetext{
${ }^{3}$ Real GDP data are: Gross Domestic Product, Expenditure approach, Millions of national currency, volume estimates, OECD reference year, annual levels, seasonally adjusted (VOBARSA). For consumption, we use Private final consumption expenditure, millions of national currency, volume estimates, OECD reference year, annual levels, seasonally adjusted (VOBARSA); hence durable, non durables and services are included.

${ }^{4}$ See Perron (2006) for a comprehensive survey related to time setries models with structural breaks.

${ }^{5}$ One could use GDP per capita instead of GDP to avoid the "re-unification effect." Although it could mitigate the problem, the issue would still present. Indeed, Stock and Watson (2005) use interpolations to deal with the "re-unification outlier" in the growth rates of per capita GDP.
} 
form of a sudden temporary drop due to the general strike in May 1968. Not surprisingly, the consumption data for each country show some degree of similarity to their corresponding GDP data.

Finally, the impact of the recent world recession that started in 2008 should be taken into consideration. Although it is close to the end of our sample period, Figure 1 clearly shows the decline in output for almost all countries. It may be a slope change, a level shift, or an outlier. We shall consider the treatment for this event within our framework in order to measure business cycles.

What we wish to highlight from this visual inspection of the series are the following facts: structural changes in the slope and level of the trend function and outliers seem to be features affecting all real GDP and consumption series for the G7 countries (though not all features are present for all series). Also, large occurrences of such features are relatively rare, mostly once and at most a few times in the postwar sample.

These features first suggest the distinct possibility that standard methods of detrending such as the HP filter will provide a distorted picture of the cyclical component. Take for instance the case of Germany. As we shall see, the HP detrending procedure is unable to account for the sudden increase at the time of the re-unification. Instead a smooth trend is fitted with the implication that the period a few quarters before 1991 was a deep recession and the period a few quarters after was a drastic short-lived expansion. Perron and Wada (2009) documents extensively, for the case of the US, how a single change in slope can affect the outcome of various detrending procedures and that accounting for such a change can drastically alter the resulting cyclical component. So, clearly, slope and level changes, as well as major outliers, can have a substantial impact on what a detrending procedure delivers as the cycle.

In many instances researchers aware of such problems will use ad hoc methods to provide a remedial; e.g., avoiding the period contaminated by such effects, interpolating (c.f., Stock and Watson, 2005) or using sub-samples. But these involve a substantial loss of information. One would therefore like to have a detrending method that is able to account for such features in an endogenous fashion, i.e., without having to specify a break date, a type or a number of changes, and deliver a cyclical component uncontaminated by these events. On this front little has been done ${ }^{6}$ and our aim is to suggest a procedure for doing so.

\footnotetext{
${ }^{6}$ A recent exception is Giordani, Kohn and van Dijk (2007) who use a Bayesian methodology applied to an extended state space model to deal with structural breaks and outliers for the variables in growth rates.
} 


\section{The trend-cycle decomposition framework}

In this section, we present the statistical model adopted. We start with the most general specification in Section 3.1 and discuss how we selected relevant special cases for each country in Section 3.2.

\subsection{The model}

The most general specification of the class of models considered is the following:

$$
\begin{aligned}
y_{t} & =\tau_{t}+c_{t}+\omega_{t} \\
\tau_{t} & =\tau_{t-1}+\beta_{t}+\eta_{t} \\
\beta_{t} & =\beta_{t-1}+v_{t} \\
\phi(L) c_{t} & =\epsilon_{t},
\end{aligned}
$$

where $y_{t}$ is the observed series, $\tau_{t}$ is the trend function, $c_{t}$ is the cyclical component and $\omega_{t}$ the measurement errors. The shocks $\omega_{t}, \eta_{t}, v_{t}$ and $\epsilon_{t}$ are assumed to be mutually uncorrelated as well as serially uncorrelated. If the errors were normally distributed, this would be a standard unobserved components model which has already been used extensively in the literature under various levels of generality (see, among others, Clark, 1987, Morley et al., 2003, Harvey and Jaeger, 1993). Our departure from the basic specification is to model the errors as having a mixture of normals distributions. ${ }^{7}$ Let $x_{t}$ represent either $\omega_{t}, \eta_{t}, v_{t}$ or $\epsilon_{t}$, the distribution of $x_{t}$ is specified to be

$$
x_{t}=\lambda_{t} \gamma_{1 t}+\left(1-\lambda_{t}\right) \gamma_{2 t}
$$

where

$$
\gamma_{i t} \sim \text { i.i.d.N }\left(0, \sigma_{i}^{2}\right)
$$

and $\lambda_{t} \sim$ i.i.d.Bernoulli $(\alpha)$. Hence, with probability $\alpha$, the error at time $t$ is drawn from a $N\left(0, \sigma_{1}^{2}\right)$ and with probability $(1-\alpha)$ it is drawn from a $N\left(0, \sigma_{2}^{2}\right)$. This will permit sudden changes if $\alpha$ is close to 1 and $\sigma_{2}^{2}$ is much larger than $\sigma_{1}^{2}$. In this case, most of the time the errors are drawn from a low variance distribution which characterizes "normal periods"; but occasionally a large shock occurs, which characterizes "atypical events." This type of model has been used in Kitagawa (1989) who considers seasonal adjustments, Giordani et al. (2007) who pay most attention to growth rate changes using data from the G7 countries,

\footnotetext{
${ }^{7}$ Notable previous studies regarding this type of models include Kitagawa (1987), among others.
} 
Perron and Wada (2009), among others. Yet, in this paper, our main focus is the trendcycle decomposition or measuring business cycle, allowing and taking into account significant shocks that cause structural changes or outliers.

Consider the implications of such a specification for the various error terms in the model. First, if this scenario applies to the measurement errors $\omega_{t}$, this would imply small or zero measurement errors in "normal periods" and occasional outliers. Second, for the error $\eta_{t}$ affecting the trend function, this would allow a random walk component (or a deterministic trend if $\sigma_{1}^{2}=0$ ) with occasional level shifts. Third, for the error $v_{t}$ affecting the slope of the trend function, this allows small or null changes in the slope in "normal periods" with occasional large changes. Finally, a mixture of normals distribution for the error $\epsilon_{t}$ can allow for different variances in recessions and expansions (though here $\alpha$ would be the probability of being in an expansion and one would expect $\sigma_{2}^{2}$ to be larger than $\sigma_{1}^{2}$ but not by a large factor; see Perron and Wada, 2009).

Hence, the use of mixture of normal distributions for the errors is potentially a powerful tool to permit structural changes in the slope and level of the trend function as well as outliers. In contrast to the popular Markov switching type model (Hamilton, 1989, for example), it is important to note that the probabilities of the errors being drawn from one regime or the other are independent of past realizations. In our model, different regimes affect the magnitude of the shocks. This is because our goal is to have a framework that allows special events such as productivity slowdown and brief but large declines of output. In such cases, the probability that we draw errors from the large variance distribution should not be dependent of whether past draws for the errors were from the small or large variance distributions. Therefore, it is more appropriate to postulate that the probabilities for the errors being in one regime or another are independent from past realizations.

\subsection{The model selection procedure}

Such mixtures of normals distributions for the errors introduce considerable additional complexities for the estimation of the model. In particular, allowing such mixtures distributions for all components leads to an unstable algorithm. Hence, we need to restrict the model somewhat to obtain sensible outcomes. Our choice of restrictions follows from our discussion of the main features of the GDP series for the various G7 countries. In all cases, the errors $v_{t}$ affecting the slope of the trend function is modelled with a mixture of normals distribution given that slope changes are likely to be present for all countries. Then, restricting the max-

imum number of the errors that are mixture of normals distribution to be two, together with 
the observations described in the previous subsection, we apply the trend-cycle decomposition model with the cyclical component specified by an $\operatorname{AR}(2)$, i.e., $\phi(L)=1-\phi_{1} L-\phi_{2} L^{2}$, for all countries. If this specification does not fit well, more precisely the estimated slope of the trend is more volatile than the estimated cycle (i.e., $\operatorname{var}\left(\beta_{t}\right)>\operatorname{var}\left(c_{t}\right)$, measured by the sample variance of the filtered estimates), then we proceed with the following steps: 1) Preserving the mixture of normal errors $v_{t}$, we consider another error (one of $\omega_{t}, \eta_{t}$, and $\epsilon_{t}$ ) to be a mixture of normals. If 1 ) fails, then 2) we use a mixture of normals distribution only for $v_{t}$ and all other errors are assumed to be normally distributed. If 2) fails also, then, 3 ) we select an $\mathrm{AR}(1)$ cycle component and repeat 1) and 2), until the estimated slope of the trend becomes less volatile than the cycles.

The models selected are presented in Table A1 (in the appendix) together with additional restrictions needed. In all cases, except Italy and the US, the errors $\epsilon_{t}$ for the cyclical component are specified as normally distributed. By allowing a mixture of normals for the US, we relate our results to those of Perron and Wada (2009). ${ }^{8}$ We also allow a mixture of normals distribution for the error $\eta_{t}$ affecting the level of the trend function for Germany, Japan, and the UK. Finally, we allow a mixture of normals for the measurement error $\omega_{t}$ only for France since it seems the only country to have been subject to a large one-time decrease in GDP caused by the May 1968 strike. The maximum likelihood estimates for all models are presented in Table A-2.

\section{Results for the trend-cycle decompositions.}

We now present results pertaining to the trend-cycle decompositions of the Real GDP and Consumption series. We start in Section 4,1 with the Real GDP series followed by the Consumption series in Section 4.2. In both cases, we highlight the main features and the differences between our decomposition, labelled MN for Mixtures of normals, and the HP filter. The volatility of the cyclical component is analyzed in Section 4.3. Section 4.4 presents a summary and interpretation of the results along with a discussion of some features of interest.

\subsection{Real GDP}

We now present the MN trend-cycle decompositions obtained for the Real GDP series of the G7 countries. These will also be compared to the decompositions obtained using the Hodrick-

\footnotetext{
${ }^{8}$ For the US GDP, we impose the same set of restrictions as in Perron and Wada (2009). See Table A-1.
} 
Prescott filter (denoted HP) (we set the smoothed parameter $\lambda$ to be 1600, as usual). The results are presented in Figures 3 through 5.

Consider first the case of Canada. The MN decomposition shows a decrease in the rate of growth after the mid 70s, early and late 80s, for all of which increases in the growth rate follow. Overall, the fitted trend is quite similar to that using the HP filter. In the case of France, the MN decomposition easily accounts for the outlier in 1968, which the HP filter assigns to the cyclical component. Otherwise, the trend function is a straight line with a change in slope near 1973. Since the trend obtained with the HP filter follows the actual series more closely and thereby ascribes less movements to the cycle, the variance of the cycle with the $\mathrm{MN}$ decomposition is larger.

Next, the MN trend for Germany accounts for several level shifts as well as the level shift after the 1991 German reunification. The HP filter, on the other hand, yields a much smoother trend function, leaving a large part of economic fluctuations, especially downward ones, to the cycle.

In the case of Italy, the MN decomposition yields a smoother trend than the HP filter until the late 70s, while the decline in the growth rate after the 80s is accompanied with a more volatile trend for the MN decomposition, leaving smaller cycles than with the HP filter.

The trend function implied by the MN decomposition for Japan is very smooth. It consists in roughly three parts: a linear trend with high growth until 1973, followed by a linear trend with much reduced slope until the early 90s after which it exhibits a further gradual decline. The HP trend is similar, with again the exception that it is less smooth and follows the series more closely so that the cycle is somewhat less variable.

For the United Kingdom, the MN and HP trends and cycles are very different. The MN trend shows important level shifts in the early and late 80 s, after which it is simply a stable straight line, except for another level shift in the late 2000s. The difference can most easily be seen by looking at the implied cycle. According to the MN decomposition almost all the period from 1960 to the mid 80s is characterized by above trend activity, while the HP cycle shows large swings. After 1990, the HP trend is close to the MN trend, yet the large decline occurring in the late 2000s is not treated as a level shift but is attributed to the cycle. Finally, in accordance with what is documented in Perron and Wada (2009), the US trend is simply a deterministic function with a change in slope occurring in the 1970s. The HP filter again follows the actual data more closely so that the implied cycle is much less volatile than the MN cycle. 
It should be noticed, however, that historical data series are often revised. One example is Germany. An old data series taken from the same source in 2004 clearly incorporates the effect of the German reunification in 1990 (see "Germany-unrevised" in Figure 1). When applying the MN decomposition, the trend function for Germany is, as demonstrated in Figure 5, a smooth trend with two major changes: a decrease in slope near 1973 and a large increase in level in 1991 associated with the re-unification. The trend function obtained from the HP filter again follows the series closely until the early 80s (so that the cycle is again less variable) but it misses the level shift. This gives a completely different characterization of the cyclical component after the early 80s. The HP cycle shows a mild expansion for much of the 80s while the MN cycle shows an important recession. From the late 80 s to the early 90s, the HP cycle shows a decrease in activity while the MN cycle shows an increase. The period a few quarters before the re-unification is characterized by a sharp recession with the $\mathrm{HP}$ cycle and by an expansion with the MN decomposition. The period a few quarters after the re-unification is characterized by an impressive boom with the HP cycle and by a more reasonable expansion with the MN cycle. The HP cycle shows much of the later part of the 90 s to be below trend activity while the MN cycle shows a performance roughly on par with the trend level. Hence, it is clear that the failure to account for the sudden upward level shift at the time of the re-unification leads to a very different picture of the cyclical component, and as we shall see below this also has implications for cross-country correlation analyses.

\subsection{Consumption}

The trend-cycle decompositions for the consumption series are presented in Figures 6 to 8 . Consider first the case of Canada. The actual series is quite smooth but exhibits sudden changes in level and slope (early 70s, mid-70s and especially the early 80s and early 90s). Such shifts are ascribed to the trend function by the MN decomposition, with the implication that little is left for the cyclical component. A way to interpret this result is to note that the actual series is affected by important shocks that are large enough to be viewed as having a permanent effect and hence are part of the trend. The fact that little is left to the cyclical component implies that the Canadian economy adapts quickly to such permanent shocks. The HP cycle is more volatile but it is interesting to note that most of the movements occur near these periods of sudden changes in level and slope.

The French MN trend is somewhat smoother than the HP trend, albeit unlike its GDP series, the abrupt decline in 1968 is not entirely removed as an outlier, resulting in a drop in

cyclical consumption. Unlike its GDP series, the German MN trend for consumption is much 
smoother than the HP trend, while with the old data set (unrevised) the result is similar to that for output: a clear level shift in the trend function is detected. It therefore shows important differences between the MN and HP cycles. This is again due to the sudden level shift at the time of the re-unification, which has a profound impact on the HP cycle, which cannot account for it. For Italy, the HP and MN trends have roughly the same characteristics, as in the case for output, with the MN cycle having slightly higher variability than the HP cycle. In the case of Japan, the MN and HP give similar decompositions, yet the MN trend better accounts for the rapid change in growth rate occurring near 1973, as well as growth rate changes at the beginning and the middle of the 1990s.

For the United Kingdom, the MN and HP decompositions reveal quite different results. The MN trend is variable prior to the early 80s after which it becomes smoother, and the cyclical component is accordingly more variable with the MN than with the HP filter. Finally, the US trend function is again very smooth (basically a straight line with a blip in the early 80s) and, since the HP trend follows more closely the series, the cycle is accordingly more variable with MN than with $\mathrm{HP}$.

\subsection{Volatilities}

Table 1 presents summary measures of the volatility in the cyclical components of output and consumption for the full sample period 1961:1-2011:1 and five 10-years sub-periods: the 1960s (1961:1-1969:4), 1970s (1970.1-1979.4), 1980s (1980.1-1989.4), 1990s (1990.1-1999.4), 2000s (2000.1-2011.1). Correspondingly, Figures 9 and 10 plot the standard deviations of output on the horizontal axis and those of consumption on the vertical axis. The area below the 45-degree line corresponds to cases for which consumption is less volatile than output. For the full period, the volatilities of output and consumption are similar using either MN or HP, except for the output of the UK and the consumption of Canada for which MN yields small cycles; and the consumption of the US and UK for which HP yields small cycles. For the sub-samples, we generally find larger volatilities of cycles when MN is used.

Consider now the relative volatility of the cyclical components of output and consumption. Standard business cycle models suggest that the volatility of consumption should be smaller than the volatility of output since agents wish to smooth out their consumption over time. Using the MN decomposition with the full sample, this is the case for all countries but the UK and US. With the HP filter, the only difference is that the US is no longer an exception. Comparing Figures 9 with 10, we find that when MN is used the UK and US are often exceptions for the consumption smoothing, but less so when HP is used. 
Figures 11 and 12 present rolling estimates of these volatilities over the period 1961:12011:4, for output and consumption, respectively. These show, for both the MN and HP decompositions that there is a clear tendency for a decline after the mid-80s (if the World Financial Crisis of 2008 and the subsequent recession are excluded) in the volatility of output for Italy and the US. This is mostly consistent with the concept of the "Great Moderation" and the finding of Stock and Watson (2002). The same is true for consumption, but only for Germany and Italy. Hence, a finding of interest is that for most countries the decline in the variability of output and consumption is due to a decline in the variability of the trend, not the cyclical component. In most cases, the trend has become smoother during the 80s.

\subsection{Summary and interpretation of the results}

In summary, the main qualitative differences between the MN and HP trend cycle decompositions are the following. First, the MN trend function accounts well for sudden level or slope changes and outliers, and hence it yields a much smoother trend than the HP filter. In statistical terms, the random walk component is much less important, if at all present, for the majority of the countries. The HP trend follows the actual series much more closely

with the implication that more of the movements in the series are characterized as being of a permanent nature, i.e., the random walk component is much more important.

Secondly, as a consequence of this last feature, the HP filter often ascribes less movements to the cyclical component compared to the MN cycle, which shows higher variability. In particular, the rolling-averages of standard deviations (Figures 11 and 12) show that MN consumption cycles have higher volatilities than HP consumption cycles, except for Canada.

Third, the MN decomposition is able to capture sudden occasional changes in the level and slope of the trend function, while the HP filter does so in a much more gradual fashion. In such cases, especially with large level shifts, the implied cycle can be very different. The failure to account for such shifts in the trend function by the HP filter is largely responsible for the fact that HP trend contains a larger random walk component and ascribes less movements to the cycle. This follows from the results in Perron $(1989,1990)$ to the effect that unaccounted changes in a trend function biases usual statistical procedures towards accounting for such changes via a random walk or autoregressive unit root characterization. We shall see in the next section that these features have implications for the cross-countries comparisons of cyclical volatility and correlations. 


\subsubsection{Why do MN cycles have higher consumption volatilities?}

At least since Backus et al. (1992), it is a well known - or stylized - fact that fluctuations in consumption should be less volatile than those in output. This is due to a rational household's choice of smoothing consumption. Indeed, the HP cycles are generally in line with this explanation although our MN cycles shows otherwise. Even with the HP filter, consumption in emerging market is known to be more volatile than output because, as Aguiar and Gopinath (2007) argue, most shocks are permanent and, hence, households are unable to smooth their consumption. On the other hand, for developed countries the shocks are mostly transitory and, accordingly, households do not alter their consumption plans in response to such shocks. This argument explains the documented features we have. Recall that our decomposition appropriately removes sudden shocks that cause structural changes or

outliers. Therefore, unless households change their consumption plan drastically in response to large shocks that create structural change or outliers in output, it is expected that cyclical consumption has a greater variability than cyclical output. In fact, in the case of France, the abrupt decline in output is removed from its cycle, whereas cyclical consumption is affected by this shock since the decline in consumption is not large enough to be removed. Another example is the UK for which changes in the trend are accounted for in output, but not in consumption; so that changes in consumption does not abruptly change, despite such changes in output.

\subsubsection{Similarities across groups}

It is generally believed that some groups of countries share similarities in business cycles: i) European (France, Germany, and Italy); and ii) English speaking countries (or AngloSaxon countries: Canada, US and UK); see, e.g., Canova et al. (2007). From Figure 10, we confirm that, over time, there is across-the-board convergence in the volatilities of HP cycles. Yet, the MN cycles in Figure 9 indicate that: i) there is convergence in the volatilities for European cycles; but ii) there is no convergence for English speaking countries; and iii) Japan is consistently smoothing its consumption.

\section{Cross-country comparisons of cyclical movements in output and consumption}

In this section, we wish to reassess the findings about important measures of cyclical movements in output and consumption across the G7 countries using our trend-cycle decomposition. The issues to be addressed are the volatility of the cyclical components of output (real 
GDP) and consumption, and the cross-country correlations in these components.

\subsection{Consumption correlation puzzle}

Since the influential work by Backus et al. (1992), one of the well known features or "stylized facts" of the international business cycle is that cross-country consumption correlations are lower than cross-country output correlations (from an empirical analysis using an HP filter to extract the trend component). However, a general equilibrium model with risk averse agents implies that the consumption correlation should be larger than the output correlation, due to the consumption smoothing behavior of agents (see, e.g., Baxter, 1995, and Backus et al., 1995). To try to disentangle this puzzle, two avenues have been followed. The first is to introduce market frictions to the basic model which imply lower consumption correlation than with complete market. Baxter and Crucini (1995) show that if the productivity shock is a random walk without international spillover, incomplete market economies would have smaller consumption correlation than output correlation, while Lewis (1996) requires non separabilities between tradables and non tradable leisure or goods, as well as capital market restrictions to reconcile the discrepancy. Another example is Kehoe and Perri (2002), who suppose that international loans are imperfectly enforceable. In that case, also due to market frictions, the consumption correlation is not necessarily higher than that of output. Recently, Wada (2014) considers the case for which agents in a two-country model do not have perfect information about the persistence of the technology shock and shows that the puzzle can be partly explained by the agents' gradual learning about the persistence.

A second approach is to assess the reliability of the "stylized facts" using alternative econometric techniques. Ambler et al. (2004) consider the reliability of the results to using different sub-samples with a wide variety of countries. They use a standard HP filter to extract the cyclical components and their results show that the consumption-output correlation puzzle is even more pronounced, i.e., the cross-country consumption correlations are much smaller than the output correlations than previously reported. Pakko (2004) shows that the consumption correlation is not always smaller than the output correlation, depending on the frequency bands used to extract the cyclical component using a band pass type filtering procedure. It is, nevertheless, smaller when using frequency bands usually associated with the business cycle. We here pursue this sensitivity analysis to see if the detrending procedure used can yield different results or provide additional evidence for the "stylized facts."

The results of the cross-country correlations for output and consumption are presented in Tables 2-3 and Figures 13-14, where the horizontal axis measures the cross-country output 
correlation and the vertical axis measures the cross-county consumption correlation. The area above the 45-degree line indicates that the consumption correlation is higher than the output correlation. The results with the HP filter confirm the stylized fact that output correlations are higher than consumption correlations. Of the 21 cases, only one pair of countries have consumption correlation higher than output correlation, and only by a rather small margin. The results with the MN decomposition are more "encouraging" in that 5 pairs of countries have consumption correlation higher than output correlation. Still, the evidence is not entirely convincing.

Let us look at the cross-country correlations in output and consumption for different sub-periods: 1961:1-1969:4, 1970:1-1979:4, 1980:1-1989:4, 1990:1-1999:4, and 2000:1-2011:1. The results show interesting differences across sub-samples and across methods of detrending. The number of pairs of countries showing consumption correlation higher than output correlation are as follows: 7 with MN for the 1960s (6 with HP), 3 with MN for the 1970s ( 4 with HP), 5 with MN for the 1980s (8 with HP), 11 with MN for the 1990s (8 with HP), and 7 with MN for the 2000s (2 with HP). Hence, if one considers our trend-cycle decomposition, the evidence about the consumption-output correlation is much less at odds with the theoretical implications and in that sense less puzzling in the last two decades. Hence, our results provide evidence that the cross-country consumption correlation is greater than the output correlation.

\section{Concluding Remarks}

Our paper presented an alternative detrending procedure that allows for trend functions having level and slope shifts and series affected by important outliers. When applied to postwar quarterly real GDP and consumption series, we have shown that it performs well, is able to account for sudden changes and yields reasonable estimates of the cyclical component. When compared with the HP filter, a major difference is the fact that our cyclical component is more variable. This is due to the fact that the HP filter does not account well for the level and slope shifts that are present and, accordingly, often ascribes more movements to the trend leaving little to the cyclical component. Some exceptions to this rule occurs, for example with the unrevised German data for which the sudden increase in level at the time of the re-unification substantially contaminates the cyclical component obtained with the HP filter so that the latter show huge spikes near the time of the level shift.

Our decomposition can make a difference when assessing the reliability of some so-called stylized facts. When considering the relative variability of the cyclical components of con- 
sumption and output across countries, our decomposition shows some important differences. In particular, we find that i) the volatility of consumption is not necessarily smaller than that of output, ii) compared to the results obtained with the HP filter, there are more cases for which the cross-country correlation in consumption is higher than that in output, in accordance with the standard theory; and iii) unlike a majority of previous studies including Canova et al. (2007) and Stock and Watson (2005), there is not much evidence for the hypothesis that the characteristics of countries' business cycles can be categorized into three groups of countries, namely, European (France, Germany, and Italy), Japan, and English speaking countries (Canada, UK and US).

\section{References}

[1] Aguiar, M. and G. Gopinath (2007) "Emerging Market Business Cycles: The Cycle is the Trend," Journal of Political Economy 115, 69-102.

[2] Ambler, S., E. Cardia, and C. Zimmermann (2004) "International Business Cycles: What are Facts?" Journal of Monetary Economics 51, 257-276.

[3] Backus, D.K., P.J. Kehoe, and F.E. Kydland (1992) "International Real Business Cycles," Journal of Political Economy 101, 745-775.

[4] Backus, D.K., P.J. Kehoe, and F.E. Kydland (1995) "International Business Cycles: Theory and Evidence," in: Cooley, T.F. (Ed.), Frontier of Business Cycle Research, Princeton University Press, 331-356.

[5] Bai, J., R.L. Lumsdaine and J.H. Stock (1998) "Testing for and Dating Breaks in Multivariate Time Series," Review of Economic Studies 65, 395-432.

[6] Baxter, M. (1995) "International Trade and Business Cycles," in: Grossman, G.M., Rogoff, K. (Eds.), Handbook of International Economics, Vol. 3. North Holland, 18011864.

[7] Baxter, M. and M. Crucini (1995) "Business Cycles and the Asset Structure of Foreign Trade," International Economic Review 36, 821-854.

[8] Baxter, M. and R.G. King (1999) "Measuring Business Cycles: Approximate Band-Pass Filter for Economic Time Series," The Review of Economics and Statistics 79, 551-563. 
[9] Beveridge, S. and C.R. Nelson (1981) "A New Approach to Decomposition of Economic Time Series into Permanent and Transitory Components with Particular Attention to Measurement of the 'Business Cycle,"' Journal of Monetary Economics 7, 151-74.

[10] Burns, A.M. and W.C. Mitchell (1946) Measuring Business Cycles, National Bureau of Economic Research: New York.

[11] Campbell, J. and N.G. Mankiw (1987) "Are Output Fluctuations Transitory?," Quarterly Journal of Economics 102, 857-880.

[12] Canova, F., M. Ciccarelli and E. Ortega (2007) "Similarities and Convergence in G-7 Cycles," Journal of Monetary Economics 54, 850-878.

[13] Clark, P.K. (1987) "The Cycle Component of the U.S. Economic Activity," Quarterly Journal of Economics 102, 797-814.

[14] Cochrane, J. (1988) "How Big Is The Random Walk in GNP?," Journal of Political Economy 96, 893-920.

[15] Doyle, B.M. and J. Faust (2005) "Breaks in the Variability and Co-movement of G-7 Economic Growth," Review of Economics and Statistics 87, 721-740.

[16] Dueker, M. and C.R. Nelson (2006) "Business Cycle Filtering of Macroeconomic Data Via a Latent Business Cycle Index," Macroeconomic Dynamics 10, 573-94.

[17] Giordani, P., R. Kohn, and D. van Dijk (2007) "A Unified Approach to Nonlinearity, Structural Change and Outliers," Journal of Econometrics 137, 112-133..

[18] Hamilton, J.D. (1989) "A New Approach to the Economic Analysis of Nonstationary Time Series and Business Cycles," Econometrica 57, 357-384.

[19] Hamilton, J.D., D.F. Waggoner and T. Zha (2007) "Normalization in Econometrics," Econometric Reviews 26, 221-252

[20] Harrison, P.J. and C.F. Stevens (1976) "Bayesian Forecasting," Journal of the Royal Statistical Society, Series B, 38, 205-247.

[21] Harvey, A.C. and A. Jaeger (1993) "Detrending, Stylized Facts and the Business Cycle," Journal of Applied Econometrics 8, 231-247. 
[22] Harvey, A.C. and G.D.A. Phillips (1979) "The Estimation of Regression Models with Autoregressive-Moving Average Disturbances," Biometrika 66, 49-58.

[23] Hodrick, R. and E. Prescott (1997) "Postwar US Business Cycles: An Empirical Investigation," Journal of Money, Credit, and Banking 29, 1-16.

[24] Kailath, T., A. H. Sayed, and B. Hassibi (2000) Linear Estimation, Prentice Hall.

[25] Kehoe, P. and F. Perri (2002) "International Business Cycles with Endogenous Incomplete Markets," Econometrica 70, 907-928.

[26] Kim, C.-J. (1994) "Dynamic Linear Models with Markov Switching," Journal of Econometrics $60,1-22$.

[27] Kim, C.J. and C. Nelson (1999) State-Space Models with Regime Switching. Cambridge: MIT Press.

[28] Kitagawa, G. (1987) "Non-Gaussian State-Space Modeling of Nonstationary Time Series," Journal of the American Statistic Association 82, 1032-1063.

[29] Kitagawa, G. (1989) "Non-Gaussian Seasonal Adjustment," Computers and Mathematics with Applications 18, 503-514.

[30] Kitagawa, G. (1994) "Two-Filter Formula for Smoothing and an Implementation of the Gaussian-Sum Smoother," Annals of Institute of Mathematical Statistics 46, 605-623.

[31] Koopman, S. J. (1997) "Exact Initial Kalman Filtering and Smoothing for Nonstationary Time Series Models," Journal of the American Statistical Association, 92, 1630-1638.

[32] Lewis, K. (1996) "What Can Explain the Apparent Lack of International Consumption Risk Sharing?" Journal of Political Economy 104, 267-297.

[33] Luo, S. and R. Startz (2013) "Is It One Break or Ongoing Permanent Shocks That Explains U.S. Real GDP," University of California, Santa Barbara, Working Paper.

[34] Mitra, S. and T.M. Sinclair (2012) "Output Fluctuations In The G-7: An Unobserved Components Approach," Macroeconomic Dynamics 16, 396-422. 
[35] Morley, J.C., C.R. Nelson and E. Zivot (2003) "Why are Beveridge-Nelson and Unobserved-Component Decompositions of GDP so Different?," Review of Economics and Statistics 85, 235-243.

[36] Pakko, M. R. (2004) "A Spectral Analysis of the Cross-Country Consumption Correlation Puzzle," Economics Letters 84, 341-347.

[37] Perron, P. (1989) "The Great Crash, the Oil Price Shock and the Unit Root Hypothesis," Econometrica 57, 1361-1401.

[38] Perron, P. (1990) "Testing for a Unit Root in a Time Series with a Changing Mean," Journal of Business and Economic Statistics 8, 153-162.

[39] Perron, P. (1997) "Further Evidence on Breaking Trend Functions in Macroeconomic Variables," Journal of Econometrics 80, 355-385.

[40] Perron, P. (2006) "Dealing with Structural Breaks". In Palgrave Handbook of Econometrics, vol. 1: Econometric Theory, K. Patterson and T.C. Mills (eds.), Palgrave Macmillan, 278-352.

[41] Perron, P. and T. Wada (2009) "Let's Take a Break: Trends and Cycles in US Real GDP," Journal of Monetary Economics 56, 749-765.

[42] Perron, P. and T. Yabu (2009) "Testing for Shifts in Trend with an Integrated or Stationary Noise Component," Journal of Business and Economic Statistics 27, 369396.

[43] Stock, J.H. and M.W. Watson (2002) "Has the Business Cycle Changed and Why?" in NBER Macroeconomics Annual 17, M. Gertler and K. Rogoff (eds.), MIT press, $159-218$.

[44] Stock, J.H. and M.W. Watson (2005) "Understanding Changes in International Business Cycle Dynamics," Journal of the European Economic Association 3, 968-1006.

[45] Wada, T. (2014) "The Role of Transitory and Persistent Shocks in the Consumption Correlation and International Comovement Puzzles," Macroeconomic Dynamics, forthcoming.

[46] Watson, M.W. (1986) "Univariate Detrending Methods with Stochastic Trend," Journal of Monetary Economics 18, 49-75. 


\section{A-1 Appendix: Estimation method ${ }^{9}$}

For concreteness, we discuss the method for the case where the shocks $\eta_{t}$ (to the level of the trend) and $v_{t}$ (to the slope of the trend) have a mixture of normals distributions and the measurement errors $\omega_{t}$ and shock to the cyclical component $\epsilon_{t}$ are normally distributed (for the other cases, only minor modifications are needed). As a matter of notation we let $\alpha_{1}$ (resp., $\alpha_{2}$ ) be the probability that a draw for $\eta_{t}$ (resp., $v_{t}$ ) comes from the low variance regime denoted $\sigma_{\eta 1}^{2}$ and $\sigma_{v 1}^{2}$ (while the higher variances are denoted $\sigma_{\eta 2}^{2}$ and $\sigma_{v 2}^{2}$ ). The State Space model is of the form

$$
\begin{aligned}
& y_{t}=H x_{t}+\omega_{t} \\
& x_{t}=F x_{t-1}+G u_{t}
\end{aligned}
$$

where $x_{t}=\left[\tau_{t}, \beta_{t}, c_{t}, c_{t-1}\right]^{\prime}, H=[1,0,1,0]$

$$
F=\left[\begin{array}{cccc}
1 & 1 & 0 & 0 \\
0 & 1 & 0 & 0 \\
0 & 0 & \phi_{1} & \phi_{2} \\
0 & 0 & 1 & 0
\end{array}\right] \quad G=\left[\begin{array}{ccc}
1 & 0 & 0 \\
0 & 1 & 0 \\
0 & 0 & 1 \\
0 & 0 & 0
\end{array}\right]
$$

and $u_{t}=\left[\eta_{t}, v_{t}, \epsilon_{t}\right]^{\prime}$. What is different from the usual State Space model is that the distribution of $u_{t}$ is not normal. However, we can view the specification as a State Space model with normal errors but with four possible states. These states are defined by the combined values of the Bernoulli random variables and imply four possible covariance matrices for the vector of errors $u_{t}$, namely

$Q=\left\{\left[\begin{array}{ccc}\sigma_{\eta 1}^{2} & 0 & 0 \\ 0 & \sigma_{v 1}^{2} & 0 \\ 0 & 0 & \sigma_{\epsilon}^{2}\end{array}\right], \quad\left[\begin{array}{ccc}\sigma_{\eta 1}^{2} & 0 & 0 \\ 0 & \sigma_{v 2}^{2} & 0 \\ 0 & 0 & \sigma_{\epsilon}^{2}\end{array}\right], \quad\left[\begin{array}{ccc}\sigma_{\eta 2}^{2} & 0 & 0 \\ 0 & \sigma_{v 1}^{2} & 0 \\ 0 & 0 & \sigma_{\epsilon}^{2}\end{array}\right], \quad\left[\begin{array}{ccc}\sigma_{\eta 2}^{2} & 0 & 0 \\ 0 & \sigma_{v 2}^{2} & 0 \\ 0 & 0 & \sigma_{\epsilon}^{2}\end{array}\right]\right\}$

where each component occurs with probabilities $\alpha_{1} \alpha_{2}, \alpha_{1}\left(1-\alpha_{2}\right),\left(1-\alpha_{1}\right) \alpha_{2}$, and $\left(1-\alpha_{1}\right)\left(1-\alpha_{2}\right)$, respectively. This interpretation is helpful in constructing an algorithm for estimation.

Our generalization complicates the estimation procedure considerably. The basic principles are, however, the same as for the estimation of the usual State Space model with

\footnotetext{
${ }^{9}$ Some explanations and descriptions of the model in this section are from Section 5 of Perron and Wada (2009).
} 
normal errors. The likelihood function is estimated using a variant of the Kalman filter and a by-product is an estimate of the conditional expectation of the state vector $x_{t}$ using information available up to time $t$. These are denoted $x_{t \mid t}$ and are called filtered estimates. One can also construct estimates using the full sample, i.e., $x_{t \mid T}$ which are obtained using a smoothing algorithm and are, accordingly, called smoothed estimates. The main goal here is to obtain smoothed estimates of the trend function $\tau_{t}$ and of the cyclical component $c_{t}$. We describe the main steps below.

Since this estimation and the filtering procedure are similar to the ones for Markov switching models, the basis for the construction of our computer codes was the GAUSS program written by Chang-Jin Kim (KIM_JE1.OPT) as discussed in Kim and Nelson (1999). The code is available from the book's website. Let $Y_{t}=\left(y_{1}, \ldots, y_{t}\right)$ be the vector of data available up to time $t$. The objective function to be maximized is

$$
\begin{aligned}
\ln (L) & =\sum_{t=1}^{T} \ln p\left(y_{t} \mid Y_{t-1}\right) \\
p\left(y_{t} \mid Y_{t-1}\right) & =\sum_{s_{t}=1}^{4} \sum_{s_{t-1}=1}^{4} p\left(y_{t} \mid s_{t-1}, s_{t}, Y_{t-1}\right) \operatorname{Pr}\left(s_{t-1}=i, s_{t}=j \mid Y_{t-1}\right)
\end{aligned}
$$

Also, let the prediction errors be

$$
\nu_{t \mid t-1}^{i j}=y_{t}-E\left[y_{t} \mid Y_{t-1}, s_{t-1}=i, s_{t}=j\right]=y_{t}-H x_{t \mid t-1}^{i j} .
$$

Here, and throughout, the superscripts $(i j)$ refers to the value of the variable conditional on the process being in state $i$ at time $t-1$ and state $j$ at time $t$. Conditional on the states at periods $t$ and $t-1$ taking values $i$ and $j$, respectively, and the value of $Y_{t-1}$, the prediction errors are such that

$$
\left(\nu_{t \mid t-1}^{i j} \mid s_{t-1}=i, s_{t}=j, Y_{t-1}\right) \sim N\left(0, f_{t \mid t-1}^{i j}\right)
$$

with

$$
f_{t \mid t-1}^{i j}=E\left(\nu_{t \mid t-1}^{i j} \nu_{t-1}^{i j \prime}\right)=H P_{t \mid t-1}^{i j} H^{\prime}
$$

so that

$$
p\left(y_{t} \mid s_{t-1}, s_{t}, Y_{t-1}\right)=\frac{1}{\sqrt{2 \pi}}\left|f_{t \mid t-1}^{i j}\right|^{-1 / 2} \exp \left\{-\frac{\nu_{t \mid t-1}^{i j \prime}\left(f_{t \mid t-1}^{i j}\right)^{-1} \nu_{t-1}^{i j}}{2}\right\}
$$


Also,

$$
\begin{aligned}
\operatorname{Pr}\left(s_{t-1}=i, s_{t}=j \mid Y_{t-1}\right) & =\operatorname{Pr}\left(s_{t}=j \mid s_{t-1}=i\right) \operatorname{Pr}\left(s_{t-1}=i \mid Y_{t-1}\right) \\
& =\operatorname{Pr}\left(s_{t}=j\right) \operatorname{Pr}\left(s_{t-1}=i \mid Y_{t-1}\right) \\
\operatorname{Pr}\left(s_{t-1}=i, s_{t}=j \mid Y_{t}\right) & =\operatorname{Pr}\left(s_{t-1}=i, s_{t}=j \mid y_{t}, Y_{t-1}\right)=\frac{p\left(y_{t}, s_{t}, s_{t-1} \mid Y_{t-1}\right)}{p\left(y_{t} \mid Y_{t-1}\right)} \\
& =\frac{p\left(y_{t} \mid s_{t}, s_{t-1}, Y_{t-1}\right) \operatorname{Pr}\left(s_{t-1}=i, s_{t}=j \mid Y_{t-1}\right)}{p\left(y_{t} \mid Y_{t-1}\right)} \\
\operatorname{Pr}\left(s_{t}=j \mid Y_{t}\right) & =\sum_{i=1}^{4} \operatorname{Pr}\left(s_{t-1}=i, s_{t}=j \mid Y_{t}\right) .
\end{aligned}
$$

The basic inputs are therefore the best estimates of the sate vector and their mean squared errors, namely

$$
\begin{aligned}
& x_{t \mid t-1}^{i j}=F x_{t-1 \mid t-1}^{i} \\
& P_{t \mid t-1}^{i j}=F P_{t-1 \mid t-1}^{i} F^{\prime}+G Q^{j} G^{\prime}
\end{aligned}
$$

where

$$
\begin{aligned}
x_{t \mid t-1}^{i j} & =E\left[x_{t} \mid Y_{t-1}, s_{t-1}=i, s_{t}=j\right] \\
x_{t-1 \mid t-1}^{i} & =E\left[x_{t-1} \mid Y_{t-1}, s_{t-1}=i\right] \\
P_{t \mid t-1}^{i j} & =E\left[\left(x_{t}-x_{t \mid t-1}\right)\left(x_{t}-x_{t \mid t-1}\right)^{\prime} \mid Y_{t-1}, s_{t-1}=i, s_{t}=j\right] \\
P_{t-1 \mid t-1}^{i} & =E\left[\left(x_{t-1}-x_{t-1 \mid t-1}\right)\left(x_{t-1}-x_{t-1 \mid t-1}\right)^{\prime} \mid Y_{t-1}, s_{t-1}=i\right]
\end{aligned}
$$

for $i, j=1,2,3,4$. The problem that arises with four possible states is that the number of estimates for the state vector and their mean square error matrices grows exponentially with time. Indeed, at a given time $t$, we have $t^{4}$ estimates of the state vector to compute. The solution we adopt is to use the re-collapsing procedure suggested by Harrison and Steven (1976) which effectively provides re-approximations at each time $t$. These are given by:

$$
\begin{aligned}
x_{t \mid t}^{j} & =\frac{\sum_{i=1}^{4} \operatorname{Pr}\left(s_{t-1}=i, s_{t}=j \mid Y_{t}\right) x_{t \mid t}^{i j}}{\operatorname{Pr}\left(s_{t}=j \mid Y_{t}\right)} \\
P_{t \mid t}^{j} & =\frac{\sum_{i=1}^{4} \operatorname{Pr}\left(s_{t-1}=i, s_{t}=j \mid Y_{t}\right)\left\{P_{t \mid t}^{i j}+\left(x_{t \mid t}^{j}-x_{t \mid t}^{i j}\right)\left(x_{t \mid t}^{j}-x_{t \mid t}^{i j}\right)^{\prime}\right\}}{\operatorname{Pr}\left(s_{t}=j \mid Y_{t}\right)}
\end{aligned}
$$

where now a single superscript $j$ refers to the value of the variable conditional on the process being in state $j$ at period $t$. The filtered estimate of the state vector is then obtained as:

$$
x_{t \mid t}=\sum_{j=1}^{4} \operatorname{Pr}\left(s_{t}=j \mid Y_{t}\right) x_{t \mid t}^{j} .
$$




\section{A-2 Initial values}

Since one component of the state vector is non-stationary, we cannot initialize all components of the state vector and its covariance matrix to their unconditional expected values. Although theoretically, any value can be used for the state vector as a diffuse prior (see Kim and Nelson, 1999 or Koopman 1997, for example), we use the following approach. First, the UC model with constant drift term is estimated. From the estimated trend, we compute the mean and the variance of the slope of the trend, say, $\beta_{0}$ and $p_{0}$, respectively. To obtain these initial values, following Perron and Wada (2009), we first estimate the unobserved components model with the errors having normal distributions and a constant drift term in the trend function:

$$
\begin{aligned}
y_{t} & =\tau_{t}+c_{t} \\
\tau_{t} & =\mu+\tau_{t-1}+\eta_{t} \\
\phi(L) c_{t} & =e_{t}
\end{aligned}
$$

where $\phi(L)$ is an $\mathrm{AR}(1)$ or $\mathrm{AR}(2)$ lag-polynomial. Then, compute the filtered trend process, $\tau_{t \mid t}$, and we set $\beta_{0}=\Delta \tau_{2 \mid 2}=\tau_{2 \mid 2}-\tau_{1 \mid 1}$ and $p_{0}=\operatorname{var}\left(\Delta \tau_{t \mid t}\right)$, the sample variance of the first-differences of the filtered estimate of the element $\tau_{t}$ of the state vector. More precisely, for the $\operatorname{AR}(2)$ cycle case, the initial values we used are:

$$
x_{0 \mid 0}=\left[\begin{array}{cccc}
y_{1} & \Delta \tau_{2 \mid 2} & 0 & 0
\end{array}\right]^{\prime}
$$

and

$$
P_{0 \mid 0}=\left[\begin{array}{ccc}
1 e+08 & 0 & 0 \\
0 & \operatorname{var}\left(\Delta \tau_{t \mid t}\right) & 0 \\
0 & 0 & P
\end{array}\right]
$$

where the submatrix $P$ is given by

$$
\operatorname{vec}(P)=\left[I_{2}-F 1 \otimes F 1\right]^{-1} \operatorname{vec}(Q 1)
$$

with

$$
F 1=\left[\begin{array}{cc}
\phi_{1} & \phi_{2} \\
1 & 0
\end{array}\right] \quad Q 1=\left[\begin{array}{cc}
\sigma_{\epsilon}^{2} & 0 \\
0 & 0
\end{array}\right]
$$

The initial value of the trend $\tau_{t}$ is set to the first observation of the series and we set its variance to a very large number to reflect a diffuse prior on its value, following Harvey and 
Phillips (1979). Note that the results are not sensitive to these particular specifications. The other components of the state vector are stationary and we use their steady state values as initial conditions.

\section{A-3 Restrictions, Initial conditions and computations}

A practical difficulty in the estimation of such Gaussian mixture models is the so called "label-switching problem" (see, e.g., Hamilton, Waggoner and Zha, 2007). This problem is due to the fact that the likelihood function $p\left(y_{t} \mid Y_{t-1}\right)$ does not change if the individual components of $p\left(y_{t} \mid s_{t-1}, s_{t}, Y_{t-1}\right) \operatorname{Pr}\left(s_{t-1}=i, s_{t}=j \mid Y_{t-1}\right)$ are interchanged, and likewise for $p\left(y_{t} \mid s_{t-1}, s_{t}, Y_{t-1}\right) \operatorname{Pr}\left(s_{t-1}=i, s_{t}=j \mid Y_{t-1}\right)$, so that

$$
\begin{aligned}
& p\left(y_{t} \mid s_{t-1}, s_{t}, Y_{t-1}\right) \operatorname{Pr}\left(s_{t-1}=i, s_{t}=j \mid Y_{t-1}\right)+p\left(y_{t} \mid s_{t-1}, s_{t}, Y_{t-1}\right) \operatorname{Pr}\left(s_{t-1}=i^{*}, s_{t}=j \mid Y_{t-1}\right) \\
= & p\left(y_{t} \mid s_{t-1}, s_{t}, Y_{t-1}\right) \operatorname{Pr}\left(s_{t-1}=i^{*}, s_{t}=j \mid Y_{t-1}\right)+p\left(y_{t} \mid s_{t-1}, s_{t}, Y_{t-1}\right) \operatorname{Pr}\left(s_{t-1}=i, s_{t}=j \mid Y_{t-1}\right)
\end{aligned}
$$

Hence, we cannot identify the sates $i$ and $i^{*}$ without some normalization. To overcome this problem, we impose some restrictions discussed next.

First, we impose $\sigma_{x 1}^{2}<\sigma_{x 2}^{2}$ for the variance of $x$, with $x$ either $\omega_{t}, \eta_{t}, v_{t}$ or $\epsilon_{t}$. It is important to note that not all parameters are identified, though the trend-cycle decomposition is. To get parameter estimates we impose the following restrictions pertaining to the parameters in the mixtures of normal distributions.

Table A1. Model Selection

\begin{tabular}{l|c|c|c|c|c|c}
\hline \hline & \multicolumn{4}{|c|}{ Output } & \multicolumn{3}{c}{ Consumption } \\
\hline Country & AR & Changes & Restrictions & AR & Changes & Restrictions \\
\hline Canada & 1 & $\mathrm{~S}$ & - & 1 & $\mathrm{~S}$ & - \\
France & 2 & $\mathrm{O}, \mathrm{S}$ & $\alpha$ (slope) $>0.5$ & 2 & $\mathrm{O}, \mathrm{S}$ & - \\
Germany & 1 & $\mathrm{~L}, \mathrm{~S}$ & - & 2 & $\mathrm{~S}$ & - \\
Italy & 2 & $\mathrm{C}, \mathrm{S}$ & - & 2 & $\mathrm{~L}, \mathrm{~S}$ & - \\
Japan & 1 & $\mathrm{~L}, \mathrm{~S}$ & - & 1 & $\mathrm{~S}$ & - \\
UK & 1 & $\mathrm{~L}, \mathrm{~S}$ & - & 2 & $\mathrm{O}, \mathrm{S}$ & - \\
US & 2 & $\mathrm{C}, \mathrm{S}$ & - & 2 & $\mathrm{C}, \mathrm{S}$ & - \\
Germany (Old) & 2 & $\mathrm{~L}, \mathrm{~S}$ & $\sigma_{v}<0.01$ & 2 & $\mathrm{~L}, \mathrm{~S}$ & $\sigma_{v}<0.01$ \\
\hline \hline
\end{tabular}

C: Asymmetric Cycle L: Level Shifts, O: Outliers, S: Slope Change. 
Note also that most of these restrictions are non-binding, with some exceptions. Though such restrictions are needed to get parameter estimates, the implied trend-cycle decomposition is not sensitive to them.

All estimations are implemented using the programming language GAUSS, UNIX version 10.0. To maximize the chances of obtaining parameter estimates that correspond to the global maximum of the likelihood function, we re-estimate the model 300 times with different initial values for the parameters that are drawn from a $N(0,9)$. The convergence criterion is set at $1 e-5$ in the GAUSS command 'optmum'. Finally, we compute the likelihood function for observations $t=3$ onwards because of potential nonstationarity.

\section{A-4 Quasi-smoothing: two filter formula}

The smoothing algorithm used is that suggested by Kitagawa (1994), which is slightly different from Kim's (1994) popular method. See also Kailath et al. (2000) for detailed explanations. We outline the main steps here. Let $Y_{t}=\left(y_{1}, \ldots, y_{t}\right)$ and $Y^{t}=\left\{y_{t}, y_{t+1}, \cdots, y_{T}\right\}$, the smoothed density is then

$$
\begin{aligned}
p\left(x_{t} \mid Y_{T}\right) & =p\left(x_{t} \mid Y_{t-1}, Y^{t}\right) \\
& =\frac{p\left(Y^{t} \mid x_{t}, Y_{t-1}\right) p\left(x_{t}, Y_{t-1}\right)}{p\left(Y_{t-1}, Y^{t}\right)} \\
& =\frac{p\left(Y^{t} \mid Y_{t-1}, x_{t}\right) p\left(x_{t} \mid Y_{t-1}\right)}{p\left(Y^{t} \mid Y_{t-1}\right)} \\
& \propto p\left(Y^{t} \mid x_{t}\right) p\left(x_{t} \mid Y_{t-1}\right) .
\end{aligned}
$$

Note that $p\left(Y^{t} \mid Y_{t-1}\right)$ does not depend on $x_{t}$, and the smoothed density is obtained by the one step ahead projection density $p\left(x_{t} \mid Y_{t-1}\right)$ and the backward filtering density, $p\left(Y^{t} \mid x_{t}\right)$. The latter is given by the backward recursion, the "updating" step

$$
\begin{aligned}
p\left(Y^{t} \mid x_{t}\right) & =p\left(Y^{t+1}, y_{t} \mid x_{t}\right) \\
& =p\left(Y^{t+1} \mid x_{t}\right) p\left(y_{t} \mid Y^{t+1}, x_{t}\right) \\
& =p\left(Y^{t+1} \mid x_{t}\right) p\left(y_{t} \mid x_{t}\right)
\end{aligned}
$$

and the preceding "one-step ahead predictor" step

$$
\begin{aligned}
p\left(Y^{t+1} \mid x_{t}\right) & =\int_{-\infty}^{\infty} p\left(Y^{t+1}, x_{t+1} \mid x_{t}\right) d x_{t+1} \\
& =\int p\left(Y^{t+1} \mid x_{t+1}\right) p\left(x_{t+1} \mid x_{t}\right) d x_{t+1},
\end{aligned}
$$


given the initial condition $p\left(Y^{T} \mid x_{T}\right)=p\left(y_{T} \mid x_{T}\right)$. Suppose the backward filtering density is given by

$$
p\left(Y^{t} \mid x_{t}\right) \propto \exp \left\{-\frac{1}{2}\left(x_{t}^{\prime} \Omega_{t \mid t} x_{t}-2 \mu_{t \mid t}^{\prime} x_{t}\right)\right\}
$$

then, the backward filtering is computed by the following procedure. First, set $\Omega_{T+1 \mid t}=0$, $\mu_{T+1 \mid T}=0$. Then,

$$
\begin{gathered}
\Omega_{t \mid t}=\Omega_{t+1 \mid t}+H^{\prime} R_{t}^{-1} H \\
\mu_{t \mid t}=\mu_{t+1 \mid t}+H^{\prime} R_{t}^{-1} y_{t} \\
\Omega_{t+1 \mid t}=F^{\prime} Q_{t+1}^{-1} F-F^{\prime} Q_{t+1}^{-1}\left(\Omega_{t+1 \mid t+1}+Q_{t+1}^{-1}\right)^{-1} Q_{t+1}^{-1} F \\
\mu_{t+1 \mid t}^{\prime}=\mu_{t+1 \mid t+1}^{\prime}\left(\Omega_{t+1 \mid t+1}+Q_{t+1}^{-1}\right)^{-1} Q_{t+1}^{-1} F .
\end{gathered}
$$

Equivalently, by setting $U_{t \mid t}=\Omega_{t \mid t}^{-1}$ and $z_{t \mid t}=\Omega_{t \mid t}^{-1} \mu_{t \mid t}$, this backward filter is computed by the following backward recursion from $t=T$ to $t=1$ :

$$
\begin{aligned}
z_{t \mid t+1} & =F^{-1} z_{t+1 \mid t+1} \\
z_{t \mid t} & =z_{t \mid t+1}+K_{t}\left(y_{t}-H z_{t \mid t+1}\right)
\end{aligned}
$$

where

$$
K_{t}=U_{t \mid t+1} H^{\prime}\left(H U_{t \mid t+1} H^{\prime}+R\right)^{-1}
$$

and

$$
\begin{aligned}
U_{t \mid t+1} & =F^{-1} U_{t+1 \mid t+1} F^{-1 \prime}+F^{-1} G Q_{t+1} G^{\prime} F^{-1 \prime} \\
U_{t \mid t} & =U_{t \mid t+1}-K_{t} H U_{t \mid t+1} .
\end{aligned}
$$

Since the one step ahead projection density $p\left(x_{t} \mid Y_{t-1}\right)$ is

$$
p\left(x_{t} \mid Y_{t-1}\right) \propto \exp \left\{-\frac{1}{2}\left(x_{t}^{\prime} P_{t \mid t-1}^{-1} x_{t}-2 x_{t \mid t-1}^{\prime} P_{t \mid t-1}^{-1} x_{t}\right)\right\},
$$

the density for (A.2) is

$$
p\left(x_{t} \mid Y_{T}\right) \propto \exp \left\{-\frac{1}{2}\left(x_{t}^{\prime}\left(\Omega_{t \mid t}+P_{t \mid t-1}^{-1}\right) x_{t}-2\left(\mu_{t \mid t}^{\prime}+x_{t \mid t-1}^{\prime} P_{t \mid t-1}^{-1}\right) x_{t}\right)\right\}
$$

and, hence, the smoothed vector $x_{t \mid T}$ is given by

$$
x_{t \mid T}=x_{t \mid t-1}+P_{t \mid t-1}\left(\Omega_{t \mid t}^{-1}+P_{t \mid t-1}\right)^{-1}\left(\Omega_{t \mid t}^{-1} \mu_{t \mid t}-x_{t \mid t-1}\right)
$$


or

$$
x_{t \mid T}=x_{t \mid t-1}+J_{t}\left(z_{t \mid t}-x_{t \mid t-1}\right)
$$

where

$$
J_{t}=P_{t \mid t-1}\left(P_{t \mid t-1}+U_{t \mid t}\right)^{-1}
$$

and its mean-squared error matrix $P_{t \mid T}$ is

$$
P_{t \mid T}=P_{t \mid t-1}-P_{t \mid t-1}\left(\Omega_{t \mid t}^{-1}+P_{t \mid t-1}\right)^{-1} P_{t \mid t-1}
$$

This involves the same algorithm as for the forward filtering procedure and we use the same collapsing method. In practice, the collapsing method is implemented using

$$
x_{t \mid T}=\sum_{i} \sum_{j} \operatorname{Pr}\left(s_{t}^{i j}\right) x_{t \mid T}^{i j}
$$

where

$$
\begin{aligned}
x_{t \mid T}^{i j} & =x_{t \mid t-1}^{i}+J_{t}^{i j}\left(x_{t \mid t}^{j}-x_{t \mid t-1}^{i}\right) \\
J_{t}^{i j} & =P_{t \mid t-1}^{i}\left(P_{t \mid t-1}^{j}+U_{t \mid t}^{i}\right)^{-1}
\end{aligned}
$$

and

$$
\begin{aligned}
\operatorname{Pr}\left(s_{t}^{i j}\right) & \equiv \operatorname{Pr}\left(s_{t}=i \mid Y_{t-1}\right) \operatorname{Pr}\left(s_{t}=j \mid Y^{t}\right) \\
& =\left(\sum_{j} \operatorname{Pr}\left(s_{t}=i, s_{t-1}=j \mid Y_{t-1}\right)\right)\left(\sum_{k} \operatorname{Pr}\left(s_{t}=j, s_{t+1}=k \mid Y^{t}\right)\right) .
\end{aligned}
$$


Table A-2: Maximum Likelihood Estimates

\begin{tabular}{|c|c|c|c|c|c|c|c|c|c|c|c|c|c|c|}
\hline & & $\sigma_{\eta}$ & $\sigma_{\eta *}$ & $\sigma_{v}$ & $\sigma_{v *}$ & $\sigma_{\varepsilon}$ & $\sigma_{\varepsilon *}$ & $\sigma_{\omega}$ & $\sigma_{\omega *}$ & $\phi_{1}$ & $\phi_{2}$ & $\alpha_{1}(\operatorname{Pr} 1)$ & $\alpha_{2}(\operatorname{Pr} 2)$ & $\mathrm{LL}$ \\
\hline \multirow[t]{2}{*}{$\mathrm{CA}$} & $\mathrm{Y}$ & $\begin{array}{l}0.000 \\
(0.456)\end{array}$ & & $\begin{array}{l}0.076 \\
(0.174)\end{array}$ & $\begin{array}{l}0.812 \\
(0.196)\end{array}$ & $\begin{array}{l}0.727 \\
(0.067)\end{array}$ & & $\begin{array}{l}0.000 \\
(0.120)\end{array}$ & & $\begin{array}{l}0.976 \\
(0.125)\end{array}$ & & $\underset{(0.102)}{0.937}\left(\sigma_{v}\right)$ & & -258.713 \\
\hline & $\mathrm{C}$ & $\begin{array}{l}0.000 \\
(0.001)\end{array}$ & & $\begin{array}{l}0.000 \\
(0.000)\end{array}$ & $\begin{array}{l}0.847 \\
(0.019)\end{array}$ & $\begin{array}{l}0.555 \\
(0.149)\end{array}$ & & $\begin{array}{l}0.293 \\
(0.167)\end{array}$ & & $\begin{array}{l}0.666 \\
(0.030)\end{array}$ & & $\underset{(0.030)}{0.933}\left(\sigma_{v}\right)$ & & -260.577 \\
\hline \multirow[t]{2}{*}{$\mathrm{FR}$} & $\mathrm{Y}$ & $\begin{array}{l}0.000 \\
(0.402)\end{array}$ & & $\begin{array}{l}0.000 \\
(0.101)\end{array}$ & $\begin{array}{l}0.248 \\
(0.301)\end{array}$ & $\begin{array}{l}0.319 \\
(0.018)\end{array}$ & & $\begin{array}{l}0.144 \\
(0.034)\end{array}$ & $\begin{array}{l}3.270 \\
(0.761)\end{array}$ & $\begin{array}{l}1.604 \\
(0.129)\end{array}$ & $\begin{array}{c}-0.650 \\
(0.098)\end{array}$ & $\underset{(0.138)}{0.952}\left(\sigma_{v}\right)^{4}$ & $\underset{(0.020)}{0.950}\left(\sigma_{\omega}\right)$ & -178.123 \\
\hline & $\mathrm{C}$ & $\begin{array}{l}0.000 \\
(0.355)\end{array}$ & & $\begin{array}{l}0.032 \\
(0.040)\end{array}$ & $\begin{array}{l}2.378 \\
(2.270)\end{array}$ & $\begin{array}{l}0.387 \\
(0.052)\end{array}$ & & $\begin{array}{l}0.000 \\
(0.148)\end{array}$ & $\begin{array}{l}0.769 \\
(0.117)\end{array}$ & $\begin{array}{l}1.406 \\
(0.145)\end{array}$ & $\begin{array}{c}-0.433 \\
(0.132)\end{array}$ & $\underset{(0.004)}{0.997}\left(\sigma_{v}\right)$ & $\underset{(0.080)}{0.690}\left(\sigma_{\omega}\right)$ & -225.321 \\
\hline \multirow[t]{2}{*}{ GE } & $\mathrm{Y}$ & $\begin{array}{l}0.067 \\
(0.028)\end{array}$ & $\begin{array}{l}1.823 \\
(0.296)\end{array}$ & $\begin{array}{l}0.000 \\
(0.005)\end{array}$ & $\begin{array}{l}0.414 \\
(0.510)\end{array}$ & $\begin{array}{l}0.706 \\
(0.107)\end{array}$ & & $\begin{array}{l}0.000 \\
(0.023)\end{array}$ & & $\begin{array}{l}0.998 \\
(0.244)\end{array}$ & & $\underset{(0.137)}{0.966}\left(\sigma_{v}\right)$ & $\underset{(0.085)}{0.800}\left(\sigma_{\eta}\right)$ & -300.807 \\
\hline & $\mathrm{C}$ & $\begin{array}{l}0.000 \\
(0.255)\end{array}$ & & $\begin{array}{l}0.000 \\
(0.470)\end{array}$ & $\begin{array}{l}0.231 \\
(0.721)\end{array}$ & $\begin{array}{l}0.187 \\
(0.042)\end{array}$ & & $\begin{array}{l}0.630 \\
(0.037)\end{array}$ & & $\begin{array}{l}1.817 \\
(0.057)\end{array}$ & $\begin{array}{c}-0.858 \\
(0.058)\end{array}$ & $\underset{(0.598)}{0.900}\left(\sigma_{v}\right)$ & & -280.836 \\
\hline \multirow[t]{2}{*}{ IT } & $\mathrm{Y}$ & $\begin{array}{l}0.445 \\
(0.138)\end{array}$ & & $\begin{array}{l}0.000 \\
(0.127)\end{array}$ & $\begin{array}{l}0.738 \\
(0.781)\end{array}$ & $\begin{array}{l}0.101 \\
(0.181)\end{array}$ & $\begin{array}{l}1.939 \\
(0.140)\end{array}$ & $\begin{array}{l}0.227 \\
(0.102)\end{array}$ & & $\begin{array}{l}1.571 \\
(0.057)\end{array}$ & $\begin{array}{c}-0.672 \\
(0.055)\end{array}$ & $\underset{(0.016)}{0.993}\left(\sigma_{v}\right)$ & $\underset{(0.038)}{0.888}\left(\sigma_{\varepsilon}\right)$ & -255.018 \\
\hline & $\mathrm{C}$ & $\begin{array}{l}0.000 \\
(0.375)\end{array}$ & $\begin{array}{l}1.342 \\
(0.439)\end{array}$ & $\begin{array}{l}0.057 \\
(1.661)\end{array}$ & $\begin{array}{l}0.057 \\
(0.019)\end{array}$ & $\begin{array}{l}0.366 \\
(0.071)\end{array}$ & & $\begin{array}{l}0.191 \\
(0.042)\end{array}$ & & $\begin{array}{l}1.614 \\
(0.086)\end{array}$ & $\begin{array}{c}-0.684 \\
(0.075)\end{array}$ & $\underset{(3.174)}{0.002}\left(\sigma_{v}\right)$ & $\underset{(0.060)}{0.917}\left(\sigma_{\eta}\right)$ & -201.218 \\
\hline \multirow[t]{2}{*}{ JA } & $\mathrm{Y}$ & $\begin{array}{l}0.031 \\
(0.286)\end{array}$ & $\begin{array}{l}2.120 \\
(0.937)\end{array}$ & $\begin{array}{l}0.000 \\
(0.092)\end{array}$ & $\begin{array}{l}0.787 \\
(0.546)\end{array}$ & $\begin{array}{l}0.854 \\
(0.109)\end{array}$ & & $\begin{array}{l}0.000 \\
(0.288)\end{array}$ & & $\begin{array}{l}0.957 \\
(0.225)\end{array}$ & & $\underset{(0.027)}{0.981}\left(\sigma_{v}\right)$ & $\underset{(0.072)}{0.917}\left(\sigma_{\eta}\right)$ & -307.606 \\
\hline & $\mathrm{C}$ & $\begin{array}{l}0.000 \\
(1.810)\end{array}$ & & $\begin{array}{l}0.000 \\
(0.033)\end{array}$ & $\begin{array}{l}7.042 \\
(3.725)\end{array}$ & $\begin{array}{l}0.759 \\
(0.078)\end{array}$ & & $\begin{array}{l}0.348 \\
(0.096)\end{array}$ & & $\begin{array}{l}0.917 \\
(0.076)\end{array}$ & & $\underset{(0.006)}{0.990}\left(\sigma_{v}\right)$ & & -296.390 \\
\hline \multirow[t]{2}{*}{ UK } & $\mathrm{Y}$ & $\begin{array}{l}0.000 \\
(0.020)\end{array}$ & $\begin{array}{l}1.489 \\
(0.232)\end{array}$ & $\begin{array}{l}0.082 \\
(0.030)\end{array}$ & $\begin{array}{l}0.082 \\
(0.014)\end{array}$ & $\begin{array}{l}0.444 \\
(0.185)\end{array}$ & & $\begin{array}{l}0.000 \\
(0.025)\end{array}$ & & $\begin{array}{l}0.991 \\
(0.319)\end{array}$ & & $\underset{(0.145)}{0.069}\left(\sigma_{v}\right)$ & $\underset{(0.206)}{0.678}\left(\sigma_{\eta}\right)$ & -265.666 \\
\hline & $\mathrm{C}$ & $\begin{array}{l}0.714 \\
(0.082)\end{array}$ & & $\begin{array}{l}0.000 \\
(0.020)\end{array}$ & $\begin{array}{l}0.000 \\
(0.131)\end{array}$ & & & $\begin{array}{l}0.000 \\
(0.166)\end{array}$ & $\begin{array}{l}2.279 \\
(0.763)\end{array}$ & $\begin{array}{l}1.832 \\
(0.112)\end{array}$ & $\begin{array}{c}-0.840 \\
(0.113)\end{array}$ & $\underset{(-)}{1.000}\left(\sigma_{v}\right)$ & $\underset{(0.025)}{0.958}\left(\sigma_{\omega}\right)$ & -285.686 \\
\hline \multirow[t]{2}{*}{ US } & $\mathrm{Y}$ & $\begin{array}{l}0.000 \\
(0.330)\end{array}$ & & $\begin{array}{c}0.000 \\
(-)\end{array}$ & $\begin{array}{l}0.168 \\
(0.157)\end{array}$ & $\begin{array}{l}0.211 \\
(0.107)\end{array}$ & $\begin{array}{l}1.074 \\
(0.156)\end{array}$ & $\begin{array}{l}0.216 \\
(0.035)\end{array}$ & & $\begin{array}{l}1.349 \\
(0.076)\end{array}$ & $\begin{array}{c}-0.438 \\
(0.073)\end{array}$ & $\underset{(-)}{0.900}\left(\sigma_{v}\right)$ & $\underset{(0.103)}{0.621}\left(\sigma_{\varepsilon}\right)$ & -235.839 \\
\hline & $\mathrm{C}$ & $\begin{array}{l}0.000 \\
(0.051)\end{array}$ & & $\begin{array}{l}0.019 \\
(0.013)\end{array}$ & $\begin{array}{l}0.019 \\
(0.027)\end{array}$ & $\begin{array}{l}0.000 \\
(0.058)\end{array}$ & $\begin{array}{l}0.700 \\
(0.004)\end{array}$ & $\begin{array}{l}0.249 \\
(0.001)\end{array}$ & & $\begin{array}{l}1.640 \\
(0.004)\end{array}$ & $\begin{array}{c}-0.653 \\
(0.003)\end{array}$ & $\underset{(-)}{1.000}\left(\sigma_{v}\right)$ & $\underset{(0.004)}{0.590}\left(\sigma_{\varepsilon}\right)$ & -194.323 \\
\hline \multirow[t]{2}{*}{ GE (unrevised) } & $\mathrm{Y}$ & $\begin{array}{l}0.000 \\
(0.994)\end{array}$ & $\begin{array}{l}5.382 \\
(0.278)\end{array}$ & $\begin{array}{c}0.000^{5} \\
(0.083)\end{array}$ & $\begin{array}{l}0.659 \\
(0.582)\end{array}$ & $\begin{array}{l}0.388 \\
(0.008)\end{array}$ & & $\begin{array}{l}0.503 \\
(0.056)\end{array}$ & & $\begin{array}{l}1.637 \\
(0.089)\end{array}$ & $\begin{array}{c}-0.699 \\
(0.065)\end{array}$ & $\underset{(0.010)}{0.994}\left(\sigma_{v}\right)$ & $\underset{(0.021)}{0.968}\left(\sigma_{\eta}\right)$ & -258.919 \\
\hline & $\mathrm{C}$ & $\begin{array}{l}0.010 \\
(1.262)\end{array}$ & $\begin{array}{l}16.300 \\
(11.151)\end{array}$ & $\begin{array}{c}0.010^{5} \\
(-)\end{array}$ & $\begin{array}{l}0.066 \\
(0.126)\end{array}$ & $\begin{array}{l}0.243 \\
(0.065)\end{array}$ & & $\begin{array}{l}0.621 \\
(0.043)\end{array}$ & & $\begin{array}{l}1.792 \\
(0.074)\end{array}$ & $\begin{array}{c}-0.824 \\
(0.078)\end{array}$ & $\underset{(3.664)}{0.002}\left(\sigma_{v}\right)$ & $\underset{(0.006)}{0.994}\left(\sigma_{\eta}\right)$ & -255.488 \\
\hline
\end{tabular}

Notes: 1) The values in the "LL" columns are the log likelihood values. 2) The values in parentheses are standard errors that are computed by the purturbation method. Due to the ill-behaved likelihood surface, we do not use the standard errors for determining whether the parameters are statistically significant. 3 ) " $\sigma_{x *}$ "stands for the larger standard diviation for the error $x$. 4) For France Y, we impose the restriction $\alpha>0.95$ for the probability of $\sigma_{v}$ and the estimate is $\alpha=0.9521$. 5) We impose $\sigma_{v}<0.01$ for unrevised-Germany C and $\mathrm{Y}$. 
Table 1: Standard Deviations of the Cyclical Component of Real GDP and Consumption

\section{a. Whole Sample}

\begin{tabular}{lllllllll}
\hline \hline a) 1961:1-2011:1 & & CA & FR & GE & IT & JP & UK & US \\
\hline Output & MN & 1.14 & 1.34 & 1.49 & 1.67 & 1.49 & 0.65 & 2.22 \\
& HP & 1.40 & 1.16 & 1.60 & 1.49 & 1.59 & 1.51 & 1.55 \\
\hline Consumption & MN & 0.55 & 1.09 & 1.43 & 1.39 & 1.19 & 4.34 & 3.36 \\
& HP & 1.17 & 0.90 & 1.26 & 1.26 & 1.20 & 1.62 & 1.26 \\
\hline Relative Std. & MN & 0.48 & 0.81 & 0.96 & 0.83 & 0.80 & 6.68 & 1.51 \\
& HP & 0.84 & 0.78 & 0.79 & 0.85 & 0.75 & 1.07 & 0.81 \\
\hline \hline
\end{tabular}

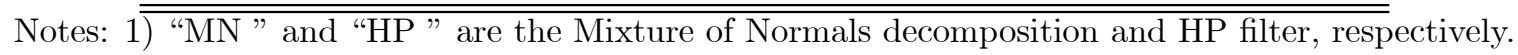
2) "Relative Std." is the standard deviation of consumption divided by the standard deviation of output. 


\section{b. Subsamples}

\begin{tabular}{lllllllll}
\hline \hline b-1) 1961:1-1969:4 & & CA & FR & GE & IT & JP & UK & US \\
\hline Output & MN & 1.04 & 0.72 & 1.09 & 1.76 & 1.40 & 0.39 & 2.50 \\
& HP & 1.04 & 1.64 & 1.85 & 1.61 & 1.57 & 1.17 & 1.14 \\
\hline Consumption & MN & 0.59 & 0.99 & 1.83 & 1.34 & 1.09 & 0.79 & 3.21 \\
& HP & 0.94 & 1.11 & 1.69 & 1.22 & 1.13 & 1.24 & 0.92 \\
\hline Relative Std. & MN & 0.57 & 1.38 & 1.68 & 0.76 & 0.78 & 2.03 & 1.28 \\
& HP & 0.90 & 0.68 & 0.91 & 0.76 & 0.72 & 1.06 & 0.81 \\
\hline \hline
\end{tabular}

\begin{tabular}{lllllllll}
\hline \hline b-2) 1970:1-1979:4 & & CA & FR & GE & IT & JP & UK & US \\
\hline Output & MN & 0.91 & 1.20 & 1.25 & 2.60 & 1.53 & 0.65 & 2.07 \\
& HP & 1.20 & 1.09 & 1.65 & 1.99 & 1.92 & 2.02 & 2.20 \\
\hline Consumption & MN & 0.64 & 0.86 & 1.81 & 1.35 & 1.51 & 2.72 & 1.93 \\
& HP & 1.30 & 1.03 & 1.61 & 1.28 & 1.86 & 2.38 & 1.80 \\
\hline Relative Std. & MN & 0.70 & 0.72 & 1.45 & 0.52 & 0.99 & 4.18 & 0.93 \\
& HP & 1.08 & 0.94 & 0.98 & 0.64 & 0.97 & 1.18 & 0.82 \\
\hline \hline
\end{tabular}

\begin{tabular}{lllllllll}
\hline \hline b-3) 1980:1-1989:4 & & CA & FR & GE & IT & JP & UK & US \\
\hline Output & MN & 1.43 & 1.30 & 1.18 & 0.74 & 1.22 & 0.83 & 2.59 \\
& HP & 2.00 & 0.84 & 1.14 & 1.18 & 1.10 & 1.52 & 1.75 \\
\hline Consumption & MN & 0.61 & 1.10 & 1.32 & 1.79 & 0.80 & 4.26 & 2.34 \\
& HP & 1.67 & 0.84 & 1.08 & 1.54 & 0.73 & 1.88 & 1.33 \\
\hline Relative Std. & MN & 0.43 & 0.85 & 1.12 & 2.42 & 0.66 & 5.13 & 0.90 \\
& HP & 0.84 & 1.00 & 0.95 & 1.31 & 0.66 & 1.24 & 0.76 \\
\hline \hline
\end{tabular}

\begin{tabular}{lllllllll}
\hline \hline b-4) 1990:1-1999:4 & & CA & FR & GE & IT & JP & UK & US \\
\hline Output & MN & 1.04 & 1.57 & 1.23 & 0.73 & 1.60 & 0.67 & 1.16 \\
& HP & 1.26 & 0.92 & 1.33 & 0.98 & 1.46 & 1.09 & 0.87 \\
\hline Consumption & MN & 0.47 & 1.44 & 0.97 & 1.46 & 1.29 & 2.15 & 1.86 \\
& HP & 0.95 & 0.89 & 0.99 & 1.37 & 1.10 & 1.07 & 0.79 \\
\hline Relative Std. & MN & 0.45 & 0.92 & 0.79 & 2.00 & 0.81 & 3.21 & 1.60 \\
& HP & 0.75 & 0.97 & 0.74 & 1.40 & 0.75 & 0.98 & 0.91 \\
\hline \hline
\end{tabular}

\begin{tabular}{lllllllll}
\hline \hline b-5) 2000:1-2011:1 & & CA & FR & GE & IT & JP & UK & US \\
\hline Output & MN & 1.00 & 1.45 & 1.33 & 1.66 & 1.25 & 0.43 & 2.03 \\
& HP & 1.29 & 1.21 & 1.91 & 1.57 & 1.77 & 1.53 & 1.50 \\
\hline Consumption & MN & 0.47 & 0.60 & 0.63 & 0.90 & 0.96 & 3.82 & 3.38 \\
& HP & 0.83 & 0.64 & 0.65 & 0.85 & 0.85 & 1.14 & 1.18 \\
\hline Relative Std. & MN & 0.47 & 0.41 & 0.47 & 0.54 & 0.77 & 8.88 & 1.67 \\
& HP & 0.64 & 0.53 & 0.34 & 0.54 & 0.48 & 0.75 & 0.79 \\
\hline \hline
\end{tabular}

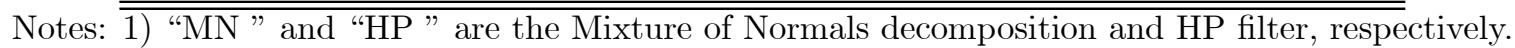

2) "Relative Std." is the standard deviation of consumption divided by the standard deviation of output. 
Table 2: Cross-Country Output and Consumption Correlations: Mixture of Normals Decomposition

\section{(Upper triangle: Consumption, Lower Triangle: Output)}

(Underlined numbers indicate consumption correlation greater than output correlation)

\begin{tabular}{lccccccc}
\multicolumn{10}{c}{ Whole Sample: 1961:1-2011:1 } \\
\hline \hline \multicolumn{1}{c}{ CA } & FR & GE & IT & JP & UK & US \\
\hline CA & & .44 & .17 & .25 & .07 & .44 & .60 \\
FR & .15 & & .60 & .46 & .41 & .37 & .47 \\
GE & .07 & .29 & & .29 & .50 & .15 & .38 \\
IT & .19 & .47 & .31 & & .37 & .05 & .24 \\
JP & -.02 & .38 & .16 & .36 & & .13 & .19 \\
UK & .11 & .42 & .13 & .25 & .08 & & .42 \\
US & .25 & .27 & .14 & .15 & .02 & .49 & \\
\hline \hline
\end{tabular}

\begin{tabular}{lccccccc}
\multicolumn{7}{c}{$1961: 1-1969: 4$} \\
\hline \hline CA & CA & FR & GE & \multicolumn{1}{c}{ IT } & \multicolumn{1}{c}{ JP } & UK & US \\
FR & .29 & .43 & .10 & .09 & -.05 & -.46 & .68 \\
GE & .06 & .02 & & -.04 & -.03 & -.01 & -.11 \\
IT & .04 & .19 & -.42 & & .60 & -.28 & -.24 \\
JP &. .03 & -.10 & -.33 & .40 & & .00 & -.18 \\
UK &.- .21 &. .39 & .28 & $\underline{-.12}$ & -.35 & & -.20 \\
US & .44 & .06 & -.52 & $\underline{-.03}$ & $\underline{.07}$ & -.42 & \\
\hline \hline
\end{tabular}

1970:1-1979:4

\begin{tabular}{lccccccc}
\hline \hline & CA & FR & GE & IT & JP & UK & US \\
\hline CA & & .59 & .56 & .24 & .31 & .35 & .60 \\
FR & .54 & & .82 & .71 & .51 & .40 & .76 \\
GE & .00 & .36 & & .47 & .55 & .61 & .78 \\
IT & .04 & .36 & .36 & & .52 & .06 & .33 \\
JP & -.12 & .23 & .10 & .22 & & .28 & .48 \\
UK & .09 & .21 & .09 & .49 & -.10 & & .44 \\
US & .28 & .68 & .48 & $\underline{.43}$ & -.06 & .54 & \\
\hline \hline
\end{tabular}

1990:1-1999:4

\begin{tabular}{lcrrrrrr}
\hline \hline & CA & FR & GE & \multicolumn{1}{l}{ IT } & \multicolumn{1}{c}{ JP } & UK & US \\
\hline CA & & .26 & -.08 & -.07 & -.22 & .78 & .71 \\
FR & -.08 & & .78 & .70 & .50 & .38 & .07 \\
GE & -.29 & $\underline{.79}$ & & .81 & .67 & .15 & -.33 \\
IT & -.09 & $\underline{.73}$ & .68 & & .69 & .17 & -.36 \\
JP &.- .06 & $\underline{.71}$ & $\underline{.78}$ & .53 & & .10 & -.39 \\
UK & .17 &. .34 & -.06 & $\underline{.52}$ & -.03 & & .61 \\
US & .24 & $\underline{.16}$ & $\underline{-.27}$ & $\underline{.26}$ & $\underline{-.28}$ & $\underline{.90}$ & \\
\hline \hline
\end{tabular}

1980:1-1989:4

\begin{tabular}{lrrrrrrr}
\hline \hline & CA & FR & GE & IT & JP & UK & US \\
\hline CA & & .29 & .54 & .49 & .52 & .46 & .77 \\
FR & -.19 & & .62 & .49 & .63 & .31 & .24 \\
GE & .38 & .27 & & .81 & .52 & .29 & .59 \\
IT & .44 & .44 & .90 & & .46 & .02 & .44 \\
JP & -.13 &. .72 & .43 & .57 & & .28 & .38 \\
UK & .24 & .48 & .24 & .28 & .24 & & .73 \\
US & .47 & -.11 & .31 & .17 & -.08 & .70 & \\
\hline \hline
\end{tabular}

2000:1-2011:1

\begin{tabular}{lccccccc}
\hline \hline & CA & FR & GE & IT & JP & UK & US \\
\hline CA & & .83 & .48 & .79 & .28 & .49 & .84 \\
FR & .56 & & .58 & .85 & .30 & .56 & .90 \\
GE & .20 & .35 & & .55 & .20 & .47 & .43 \\
IT & .55 & .74 &. .71 & & .21 & .50 & .91 \\
JP & .35 & .62 & -.19 &. .36 & & .60 & .23 \\
UK & .07 & .32 & .30 & .28 & .34 & & .52 \\
US & .24 & .43 & $\underline{.53}$ & .54 & $\underline{.31}$ & $\underline{.94}$ & \\
\hline \hline
\end{tabular}


Table 3: Cross-Country Output and Consumption Correlations: HP Filter (Upper triangle: Consumption, Lower Triangle: Output)

(Underlined numbers indicate consumption correlation greater than output correlation)

Whole Sample: 1961:1-2011:1

\begin{tabular}{lccccccc}
\hline \hline & CA & FR & GE & IT & JP & UK & US \\
\hline CA & & .39 & .34 & .43 & .24 & .55 & .75 \\
FR & .18 & & .63 & .56 & .44 & .51 & .37 \\
GE & .07 & .35 & & .47 & .53 & .44 & .41 \\
IT & .16 & .38 & .17 & & .52 & .36 & .33 \\
JP & .06 & .37 & .17 & .23 & & .43 & .35 \\
UK & .48 & .37 & .14 & .22 & .46 & & .63 \\
US & .58 & .30 & .30 & -.03 & .28 & .46 & \\
\hline \hline
\end{tabular}

1970:1-1979:4

\begin{tabular}{lrrrrrrr}
\hline \hline & CA & FR & GE & IT & JP & UK & US \\
\hline CA & & .62 & .53 & .40 & .37 & .71 & .72 \\
FR & .39 & & .83 & .72 & .57 & .66 & .63 \\
GE & -.18 & .54 & & .56 & .70 & .73 & .62 \\
IT & -.16 & .28 & .18 & & .33 & .32 & .23 \\
JP & .18 & .51 & .48 & .36 & & .59 & .57 \\
UK & .40 & .40 & .35 & .19 & .76 & & .79 \\
US & .51 & .75 & .55 & -.01 & .59 & .50 & \\
\hline \hline
\end{tabular}

\begin{tabular}{lrrrrrrr}
\hline \hline & CA & FR & GE & \multicolumn{1}{c}{ IT } & \multicolumn{1}{c}{ JP } & UK & \multicolumn{1}{c}{ US } \\
\hline CA & & .19 & .32 & .70 & .41 & .41 & .83 \\
FR & -.09 & & .08 & .47 & .43 & .39 & -.01 \\
GE &. .52 & -.07 & & .49 & .30 & -.20 & .41 \\
IT & .51 & .27 & .55 & & .42 & .31 & .52 \\
JP & -.10 &. .43 & -.02 & .06 & & -.04 & .23 \\
UK &. .59 &. .48 & .22 &. .37 &. .34 & & .42 \\
US & .60 & -.36 & .17 & -.19 & -.00 & .38 & \\
\hline \hline
\end{tabular}

1990:1-1999:4

\begin{tabular}{lccccccc}
\hline \hline & CA & FR & GE & IT & \multicolumn{1}{c}{ JP } & UK & US \\
\hline CA & & .34 & -.25 & .17 & -.26 & .84 & .76 \\
FR & .11 & & .65 & .70 & .28 & .31 & .20 \\
GE & -.36 & .41 & & .61 & .49 & -.20 & -.40 \\
IT & -.00 & .43 & .31 & & .56 & .37 & -.15 \\
JP & .17 &. .32 & .21 & .13 & & .05 & -.30 \\
UK & .72 & $\underline{.31}$ & -.28 & -.17 & $\underline{.24}$ & & .60 \\
US & .54 & $\underline{.29}$ & $\underline{-.19}$ & -.22 & $\underline{-.13}$ &. .62 & \\
\hline \hline
\end{tabular}

\begin{tabular}{lccccccc}
\multicolumn{7}{c}{$2000: 1-2011: 1$} \\
\hline \hline & CA & FR & GE & IT & JP & UK & US \\
\hline CA & & .90 & .81 & .88 & .74 & .78 & .90 \\
FR & .72 & & .92 & .95 & .75 & .84 & .88 \\
GE & .32 & .61 & & .96 & .75 & .85 & .76 \\
IT & .72 & .82 & .58 & & .83 & .87 & .85 \\
JP & .33 & .38 & -.01 & .43 & & .90 & .86 \\
UK & .80 & .68 & .24 & .69 & .63 & & .86 \\
US & .73 & .75 & .47 & .89 & .49 & .81 & \\
\hline \hline
\end{tabular}

1961:1-1969:4

\begin{tabular}{lrrrrrrr}
\hline \hline & CA & FR & \multicolumn{1}{l}{ GE } & \multicolumn{1}{l}{ IT } & \multicolumn{1}{l}{ JP } & UK & \multicolumn{1}{c}{ US } \\
\hline CA & & .07 & .26 & -.22 & -.23 & -.02 & .72 \\
FR & .04 & & .42 & .11 & .14 & .26 & -.06 \\
GE & .10 & .26 & & -.25 & .14 & .39 & .10 \\
IT &.- .39 & $\underline{.41}$ & -.34 & & .52 & -.28 & -.20 \\
JP & -.28 & $\underline{.19}$ & -.30 & .30 & & .13 & -.38 \\
UK & -.08 & .06 & -.15 & .07 & -.12 & & .00 \\
US & .73 & -.19 & .16 & -.59 & -.28 & -.15 & \\
\hline \hline
\end{tabular}

$1980: 1-1989: 4$ 

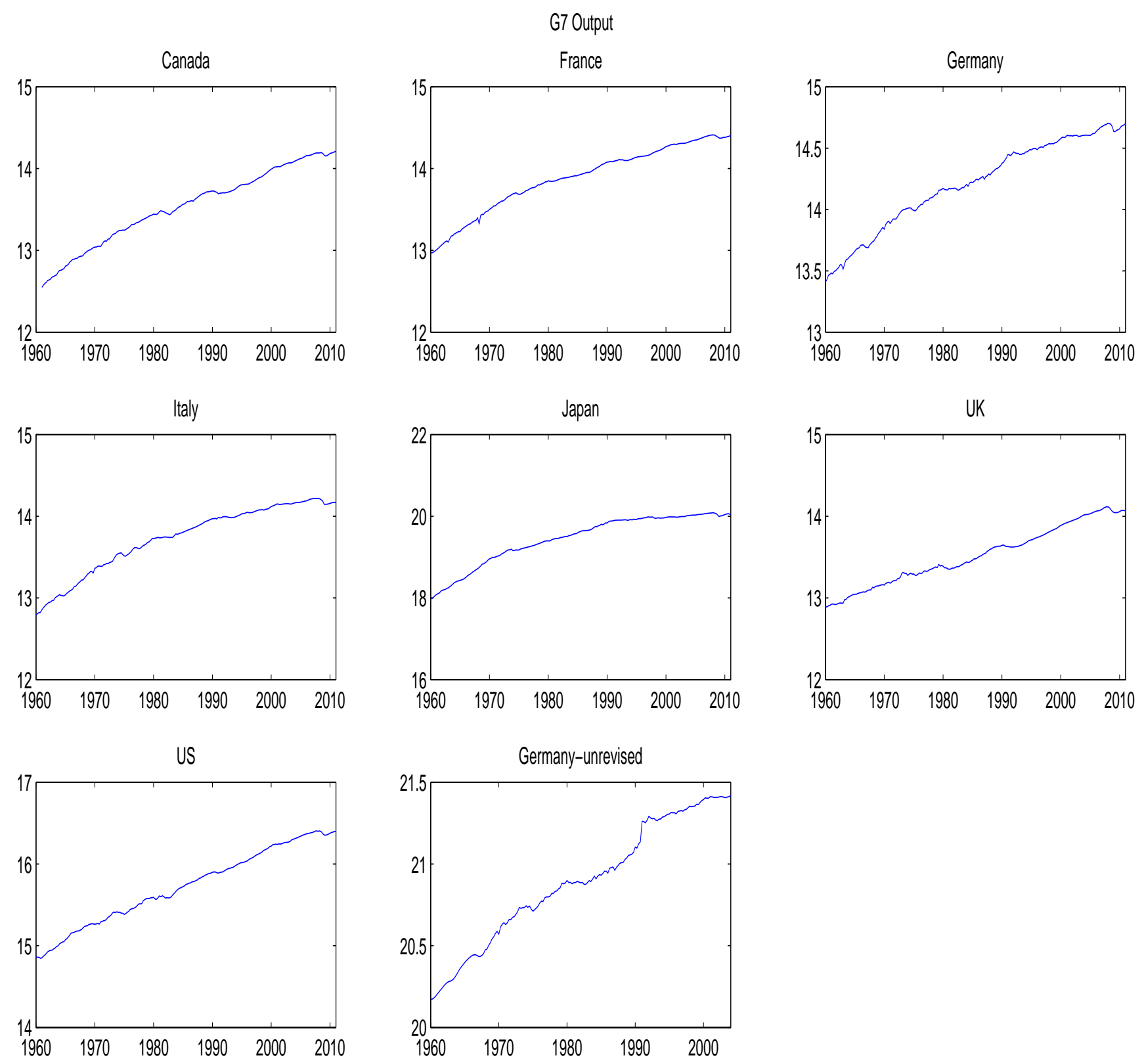

Figure 1: Postwar Quaterly (log) Real GDP Series for the G7 Countries. 

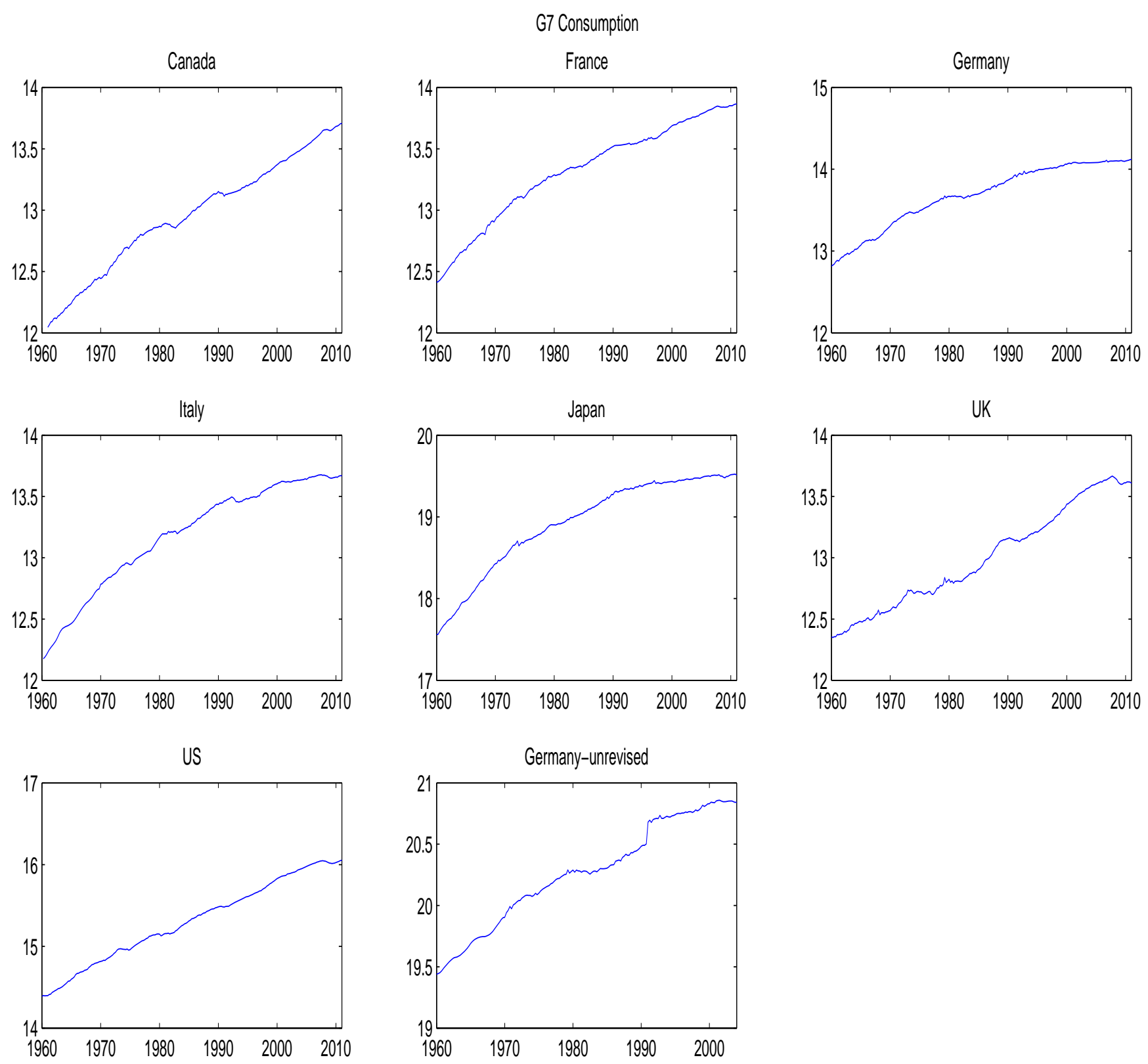

Figure 2: Postwar Quaterly (log) Real Consumption Series for the G7 Countries. 

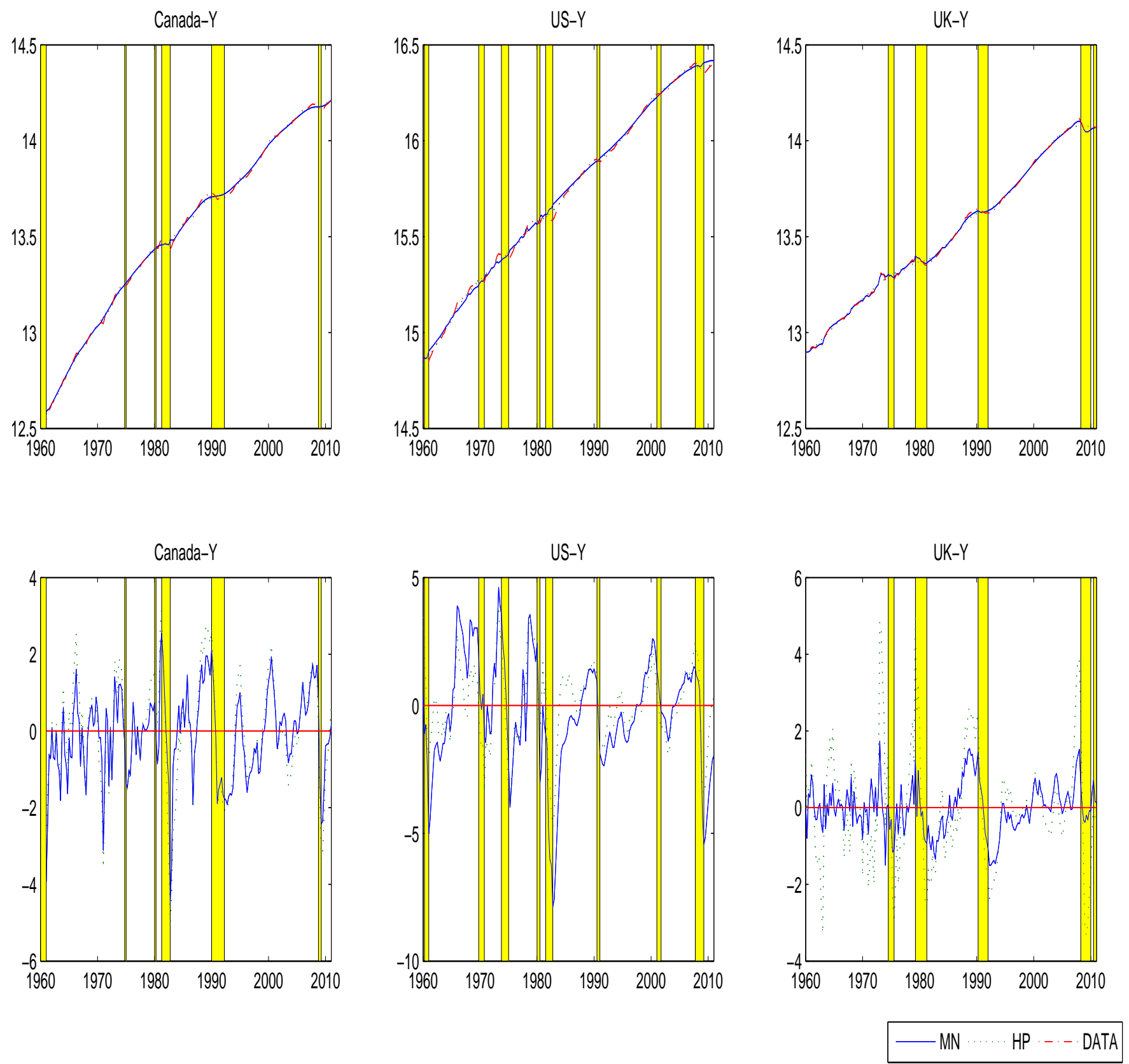

Figure 3: Trend and Cycle of Output for English Speaking Countries 

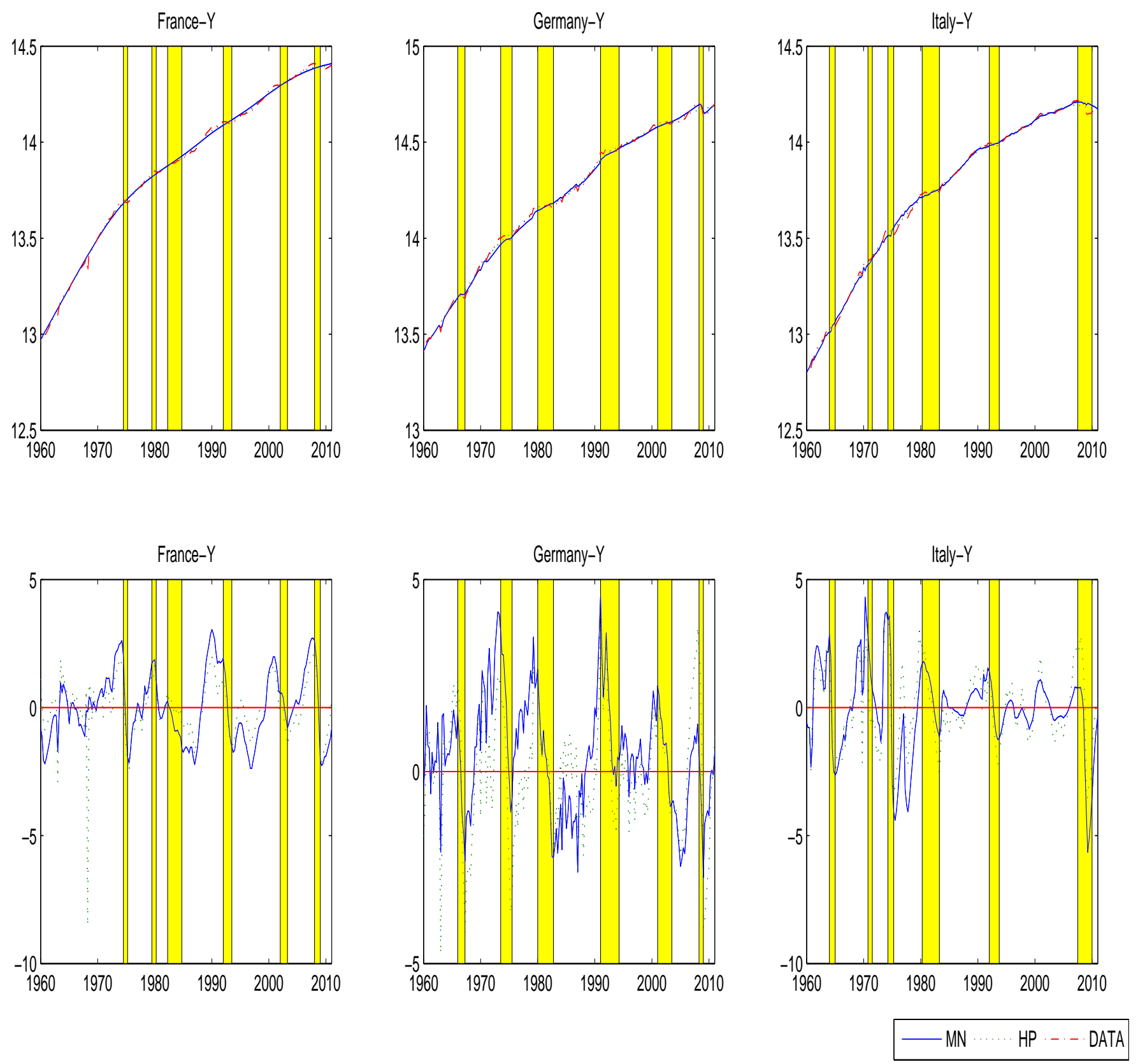

Figure 4: Trend and Cycle of Output for European Countries 

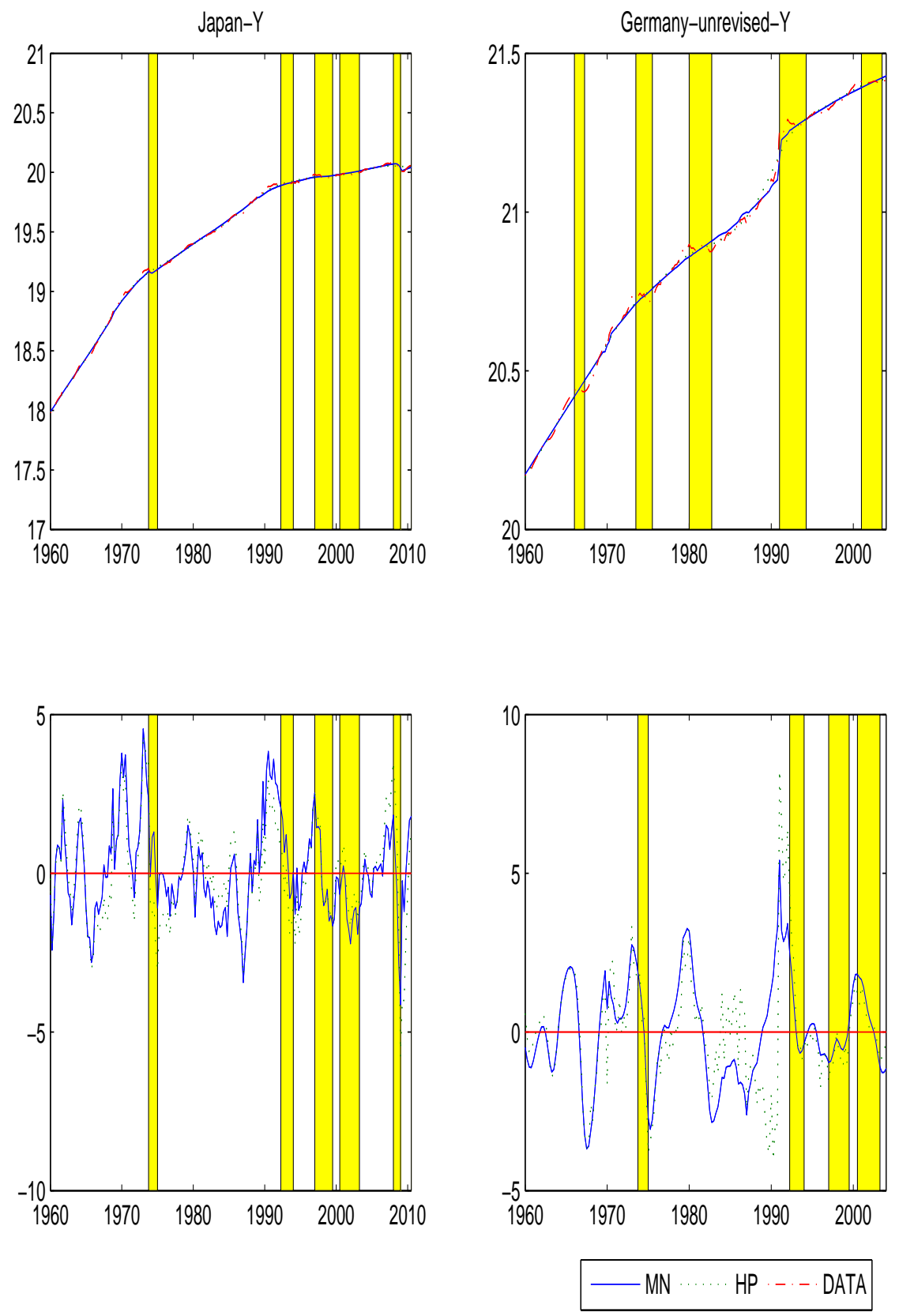

Figure 5: Trend and Cycle of Output for Japan and Unrevised German Data 

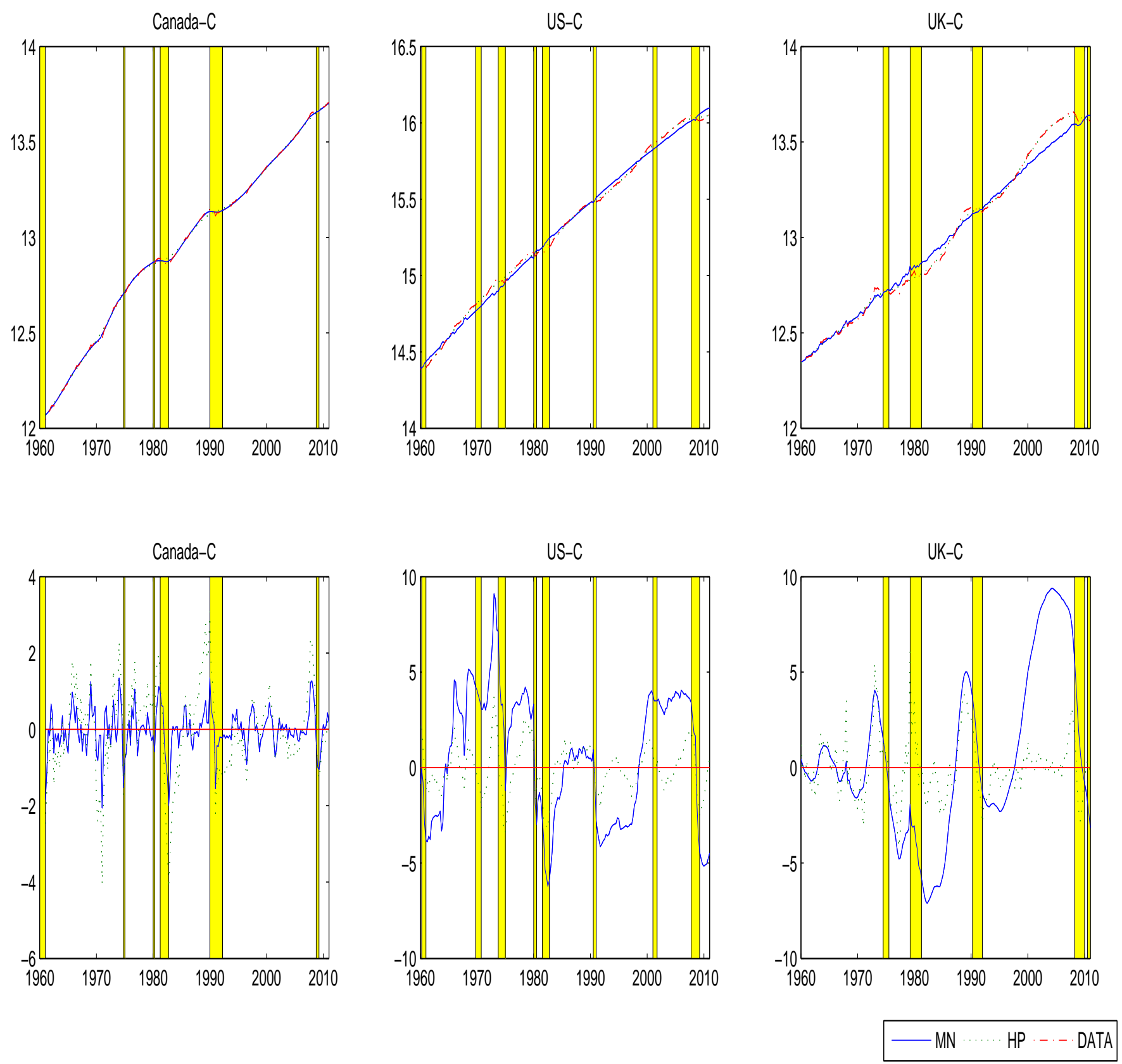

Figure 6: Trend and Cycle of Consumption for English Speaking Countries 

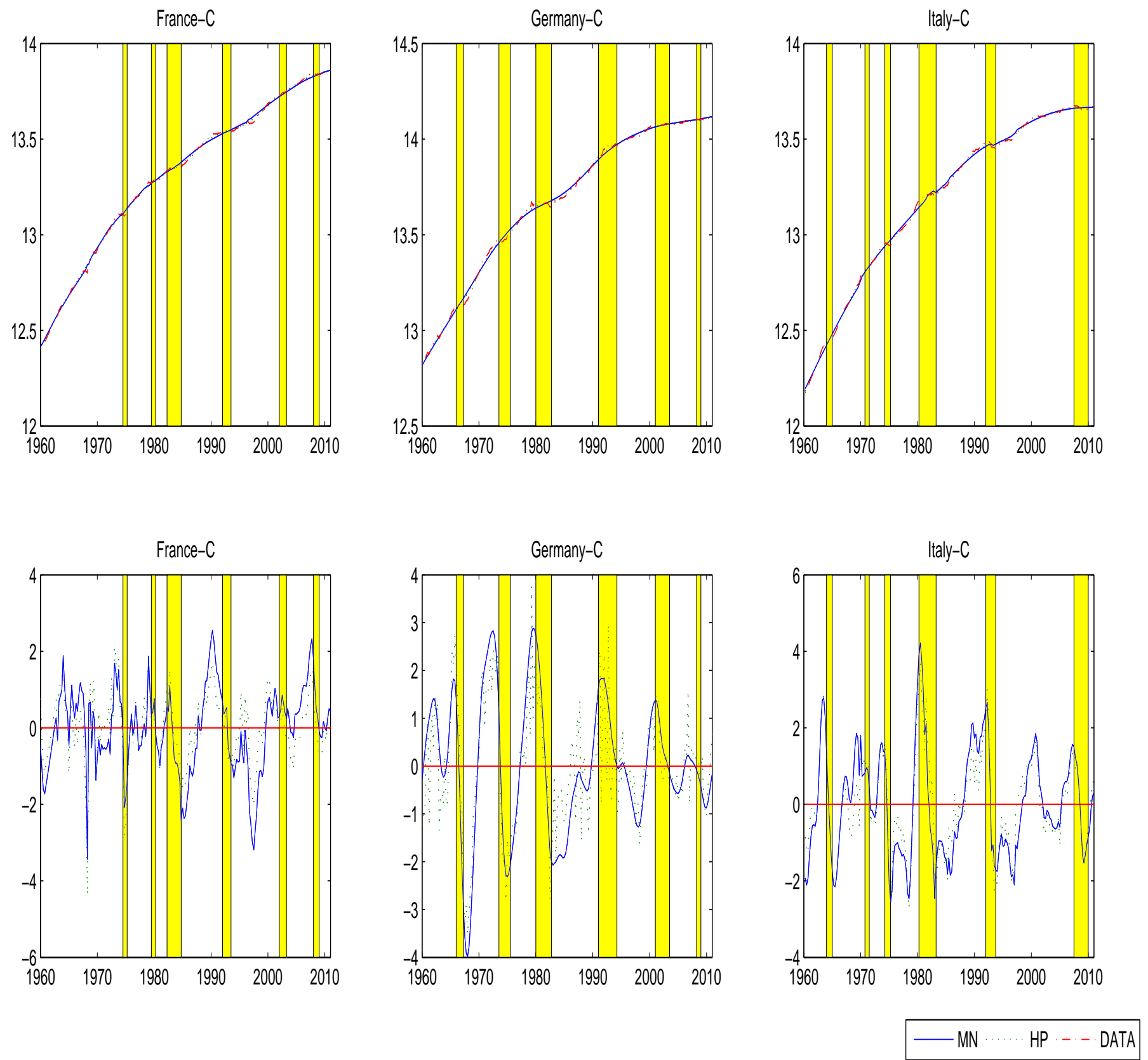

Figure 7: Trend and Cycle of Consumption for European Countries 

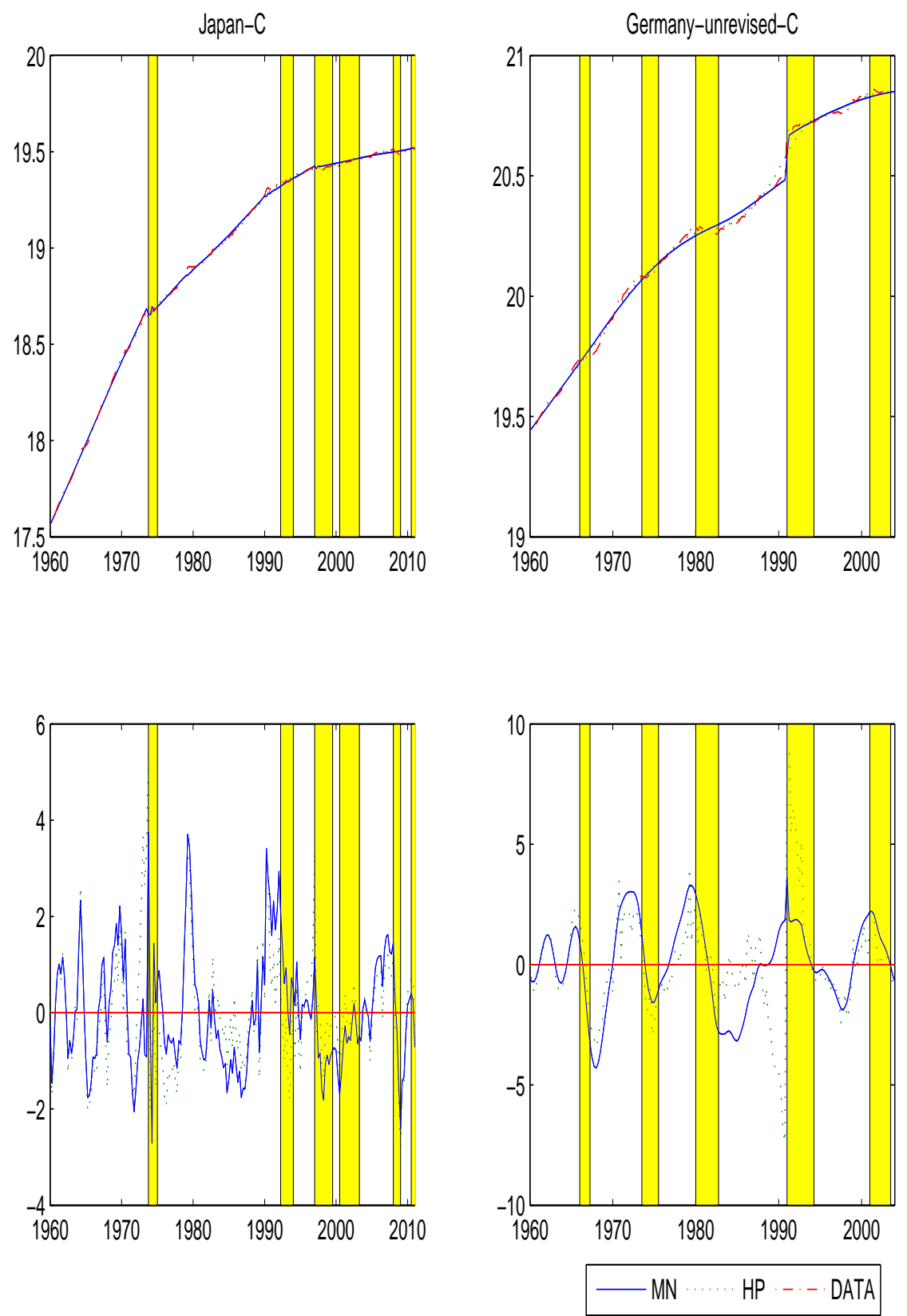

Figure 8: Trend and Cycle of Consumption for Japan and Unrevised German Data 

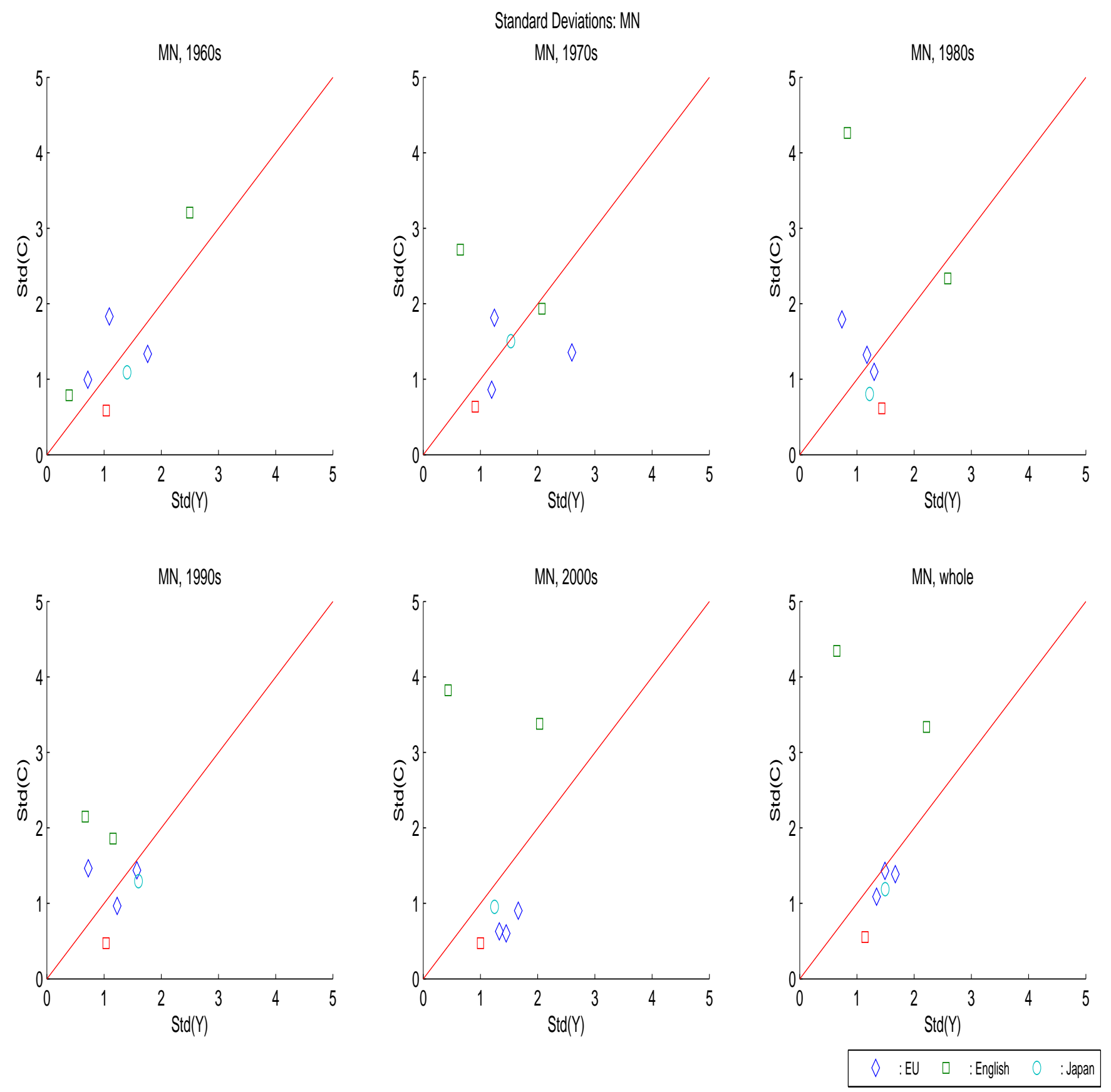

Figure 9: Standard deviations of MN filtered output (Y) and consumption (C). Daimond: EU; Square: English; Circle: Japan. 

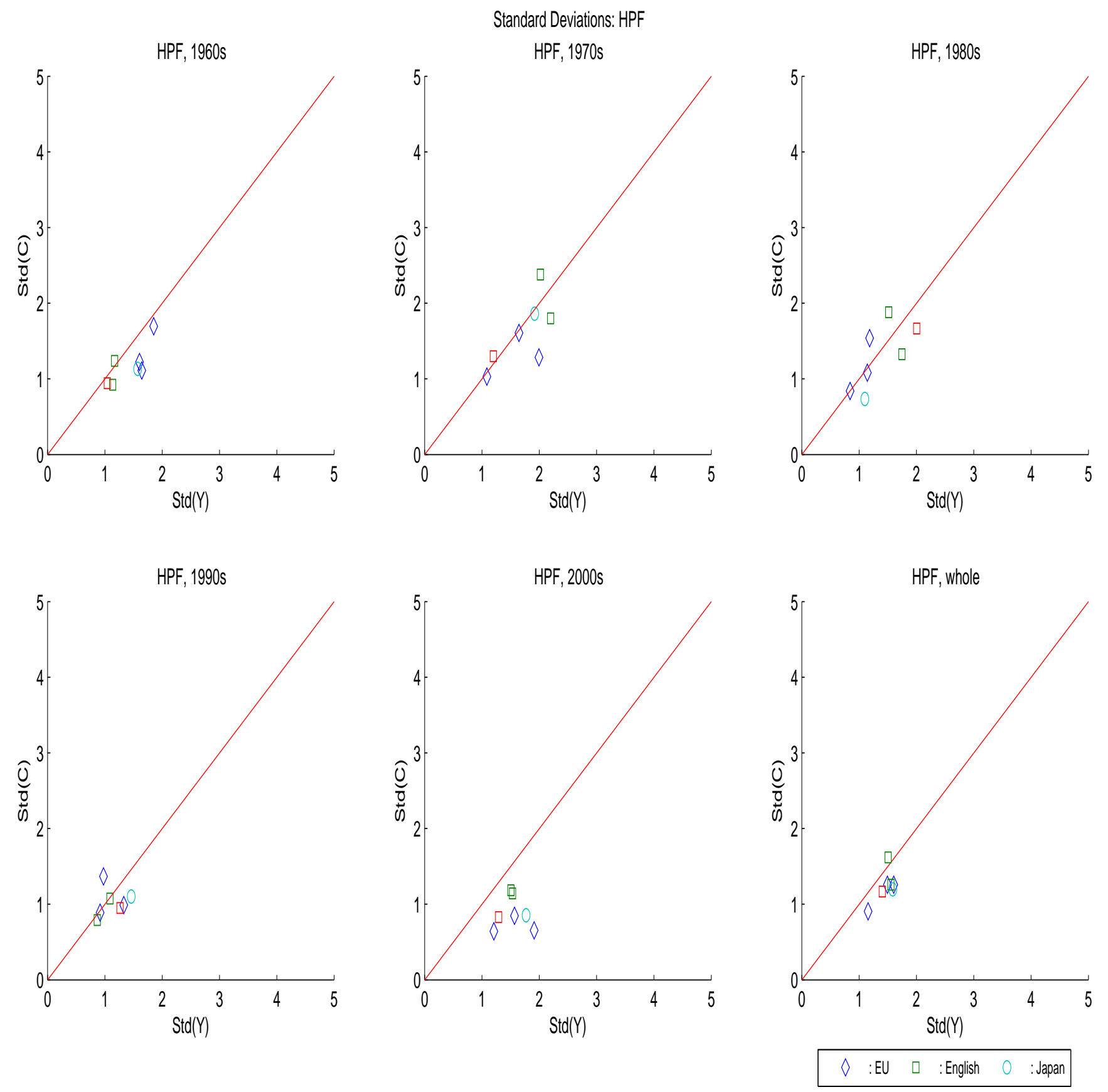

Figure 10: Standard deviations of HP filtered output (Y) and consumption (C). Daimond: EU; Square: English; Circle: Japan. 

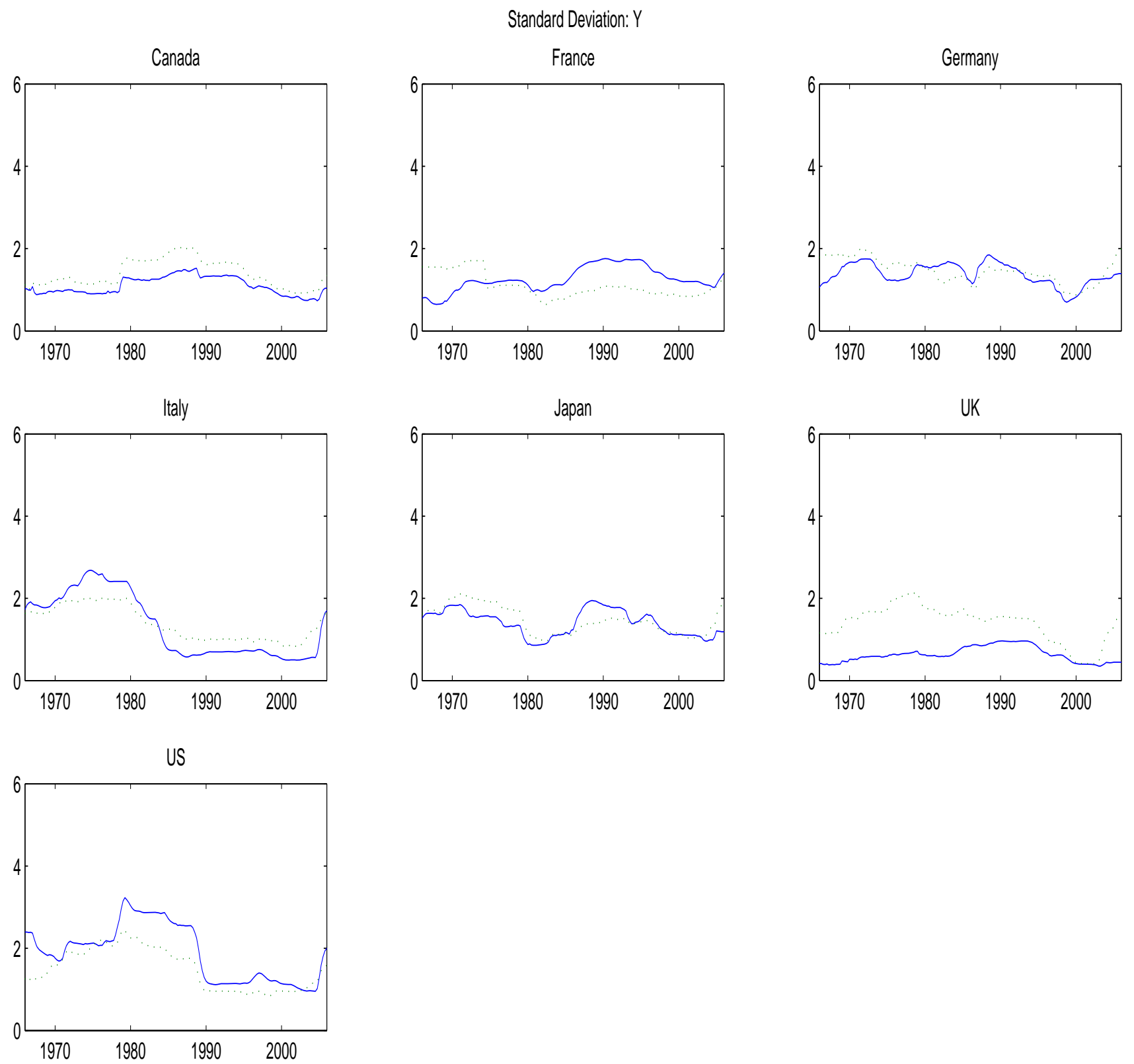

Figure 11: 10 years rolling standard deviations of the cyclical component of GDP: MN (solid) and HP (dash). 

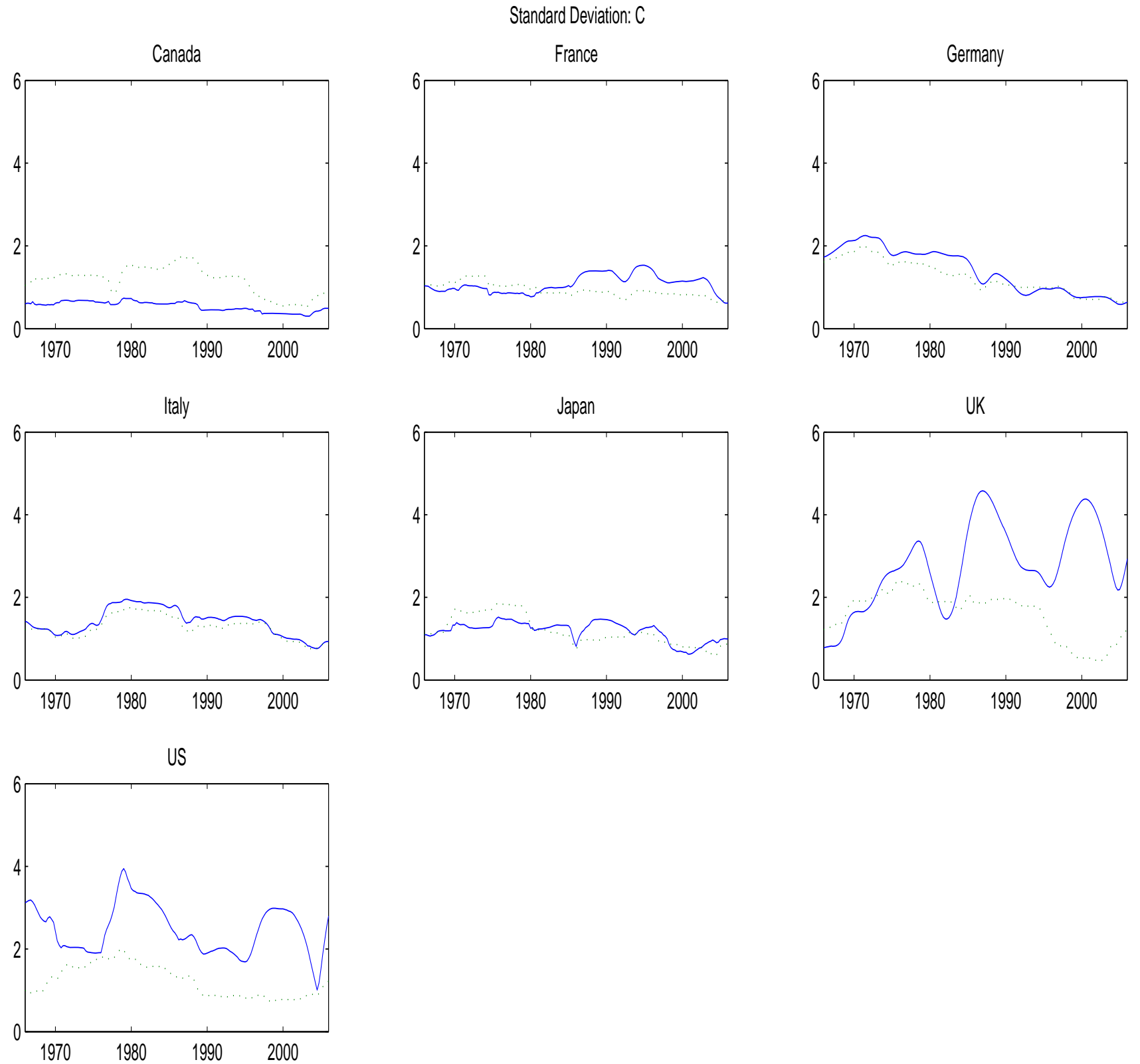

Figure 12: 10 years rolling standard deviations of the cyclical component of Consumption: MN (solid) and HP (dash). 

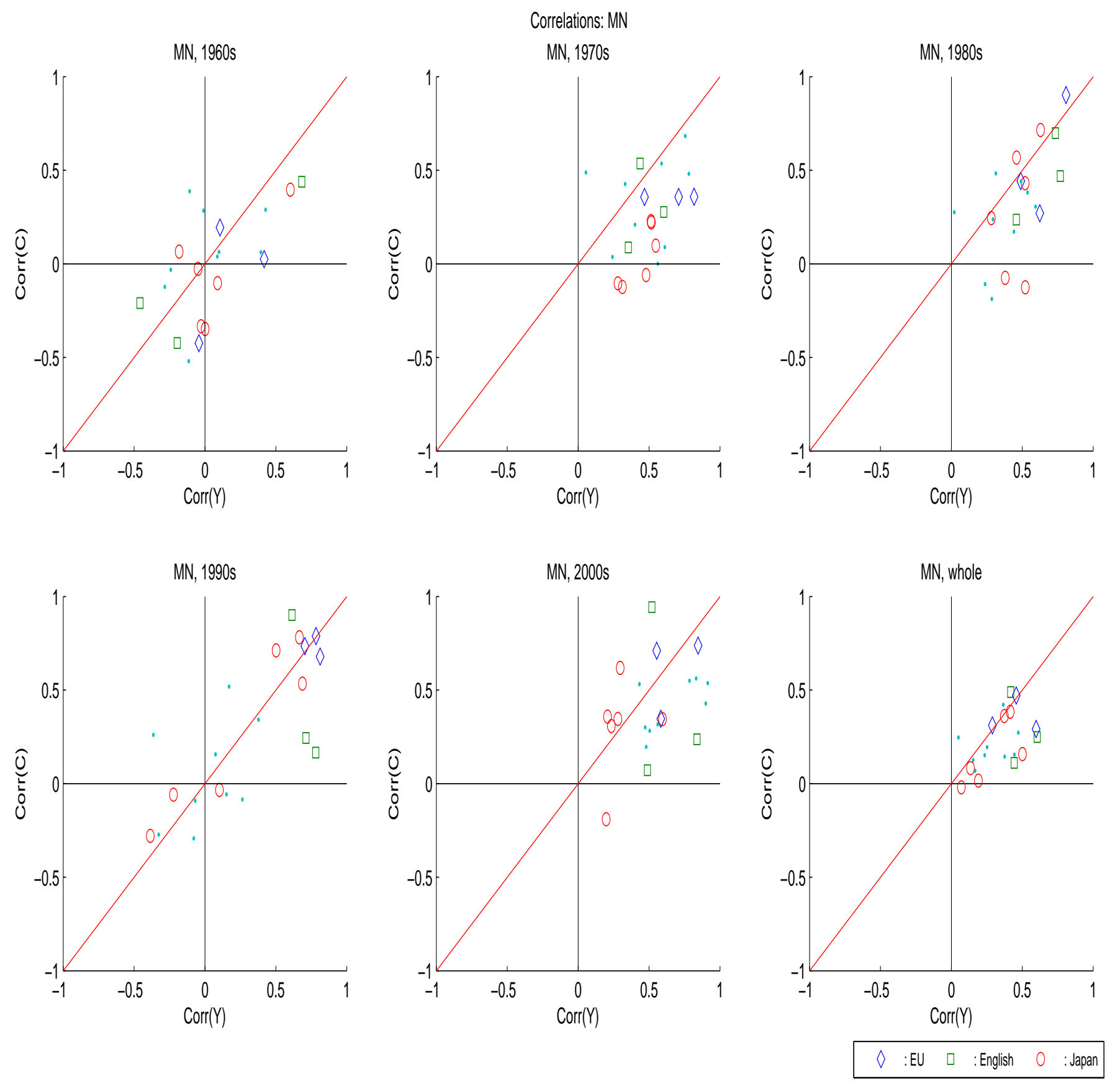

Figure 13: Correlation coefficients of MN filtered output (Y) and consumption (C). Daimond: EU; Square: English; Circle: Japan. 

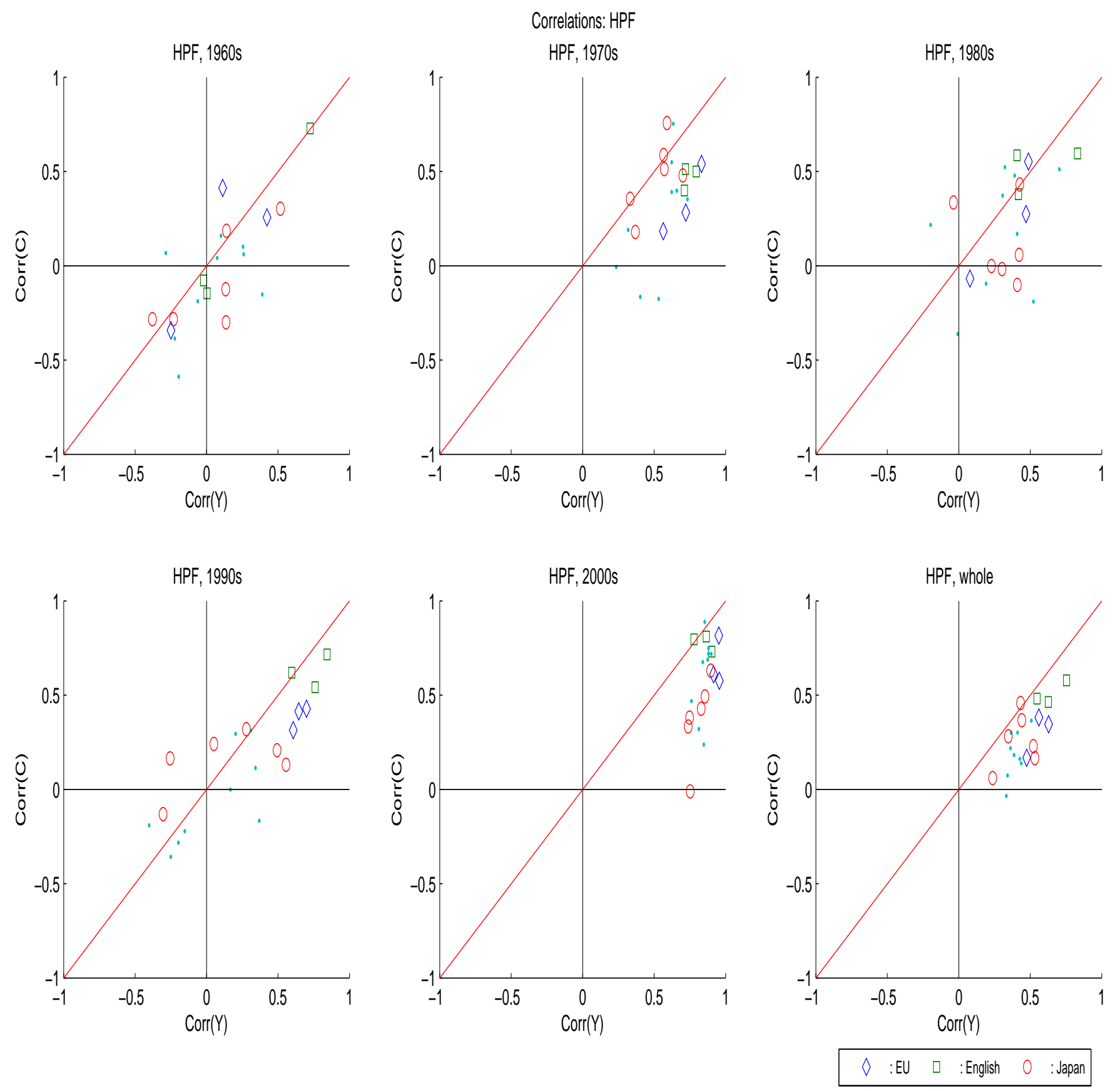

Figure 14: Correlation coefficients of HP filtered output $(\mathrm{Y})$ and consumption $(\mathrm{C})$. Daimond: EU; Square: English; Circle: Japan. 